\title{
A Semi-Automated Object-Based Approach for Landslide Detection Validated by Persistent Scatterer Interferometry Measures and Landslide Inventories
}

\author{
Daniel Hölbling $^{1, *}$, Petra Füreder ${ }^{1}$, Francesco Antolini ${ }^{2, \dagger}$, Francesca Cigna ${ }^{2,}$, Nicola Casagli ${ }^{2}$ \\ and Stefan Lang ${ }^{1}$
}

1 Z_GIS Centre for Geoinformatics, Salzburg University, Schillerstrasse 30, A-5020 Salzburg, Austria; E-Mails: petra.fuereder@sbg.ac.at (P.F.); stefan.lang@sbg.ac.at (S.L.)

2 Department of Earth Sciences, University of Firenze, Via La Pira 4, I-50121 Firenze, Italy; E-Mails: francesco.antolini@polito.it (F.A.); fcigna@bgs.ac.uk (F.C.); nicola.casagli@unifi.it (N.C.)

* Author to whom correspondence should be addressed; E-Mail: daniel.hoelbling@sbg.ac.at; Tel.: +43-662-8044-5281; Fax: +43-662-8044-5260.

$\dagger$ Present address: Politecnico di Torino, Corso Duca degli Abruzzi 24, I-10129 Torino, Italy.

† Present address: British Geological Survey, Nicker Hill, Keyworth, Nottingham NG12 5GG, UK.

Received: 29 March 2012; in revised form: 27 April 2012 / Accepted: 28 April 2012 /

Published: 7 May 2012

\begin{abstract}
Geoinformation derived from Earth observation (EO) plays a key role for detecting, analyzing and monitoring landslides to assist hazard and risk analysis. Within the framework of the EC-GMES-FP7 project SAFER (Services and Applications For Emergency Response) a semi-automated object-based approach for landslide detection and classification has been developed. The method was applied to a case study in North-Western Italy using SPOT-5 imagery and a digital elevation model (DEM), including its derivatives slope, aspect, curvature and plan curvature. For the classification in the object-based environment spectral, spatial and morphological properties as well as context information were used. In a first step, landslides were classified on a coarse segmentation level to separate them from other features with similar spectral characteristics. Thereafter, the classification was refined on a finer segmentation level, where two categories of mass movements were differentiated: flow-like landslides and other landslide types. In total, an area of $3.77 \mathrm{~km}^{2}$ was detected as landslide-affected area, $1.68 \mathrm{~km}^{2}$ were classified as flow-like landslides and $2.09 \mathrm{~km}^{2}$ as other landslide types. The outcomes were compared to and validated by pre-existing landslide inventory data (IFFI and PAI) and an interpretation
\end{abstract}


of PSI (Persistent Scatterer Interferometry) measures derived from ERS1/2, ENVISAT ASAR and RADARSAT-1 data. The spatial overlap of the detected landslides and existing landslide inventories revealed $44.8 \%$ (IFFI) and 50.4\% (PAI), respectively. About $32 \%$ of the polygons identified through OBIA are covered by persistent scatterers data.

Keywords: object-based image analysis (OBIA); landslide mapping; persistent scatterers (PS); radar-interpretation; validation

\section{Introduction}

\subsection{Background}

Gravitational mass movements such as landslides constitute a major natural hazard in all hilly or mountainous regions throughout the world. Although these movements are mostly a very local phenomenon, they cause damage to all types of man-made structures and affect infrastructures from local to regional scales and even on a national scale. The floods and landslides in China from May to August 2010 ranked second highest in terms of economic damage caused by natural disasters, with US\$ 18 billion worth of damage [1]. In the course of this natural disaster, mass movements killed 1,765 persons and ranked in the top 10 of the most important disasters by number of persons killed [1]. Landslide triggering conditions, such as heavy rain falls and typhoons or earthquakes, can affect very large areas and sometimes cause several thousand landslides per event; for example Tsai et al. [2] reported over 9,000 detected landslides after typhoon Morakot in Taiwan in August 2009.

Within the framework of the EC-GMES-FP7 project SAFER (Services and Applications For Emergency Response), where an integrated Landslide Monitoring (LM) service has been established, a semi-automated object-based approach for landslide detection has been developed for Mont de la Saxe area, Aosta Valley, Italy. Landslide Monitoring represents a thematic reference service carried out to retrieve past ground movements of single large landslides affecting built-up areas with a high level of risk. For the site of Mont de la Saxe, LM was based on the integration of object-based analysis of optical satellite images with InSAR (Interferometric Synthetic Aperture Radar) and PSI (Persistent Scatterer Interferometry) measures of ground displacements obtained from interferometric processing of radar satellite images. These input data were subsequently integrated with further ancillary data (e.g., detailed geological and geomorphological information) and in situ measurements following a consolidated methodology, in order to obtain detailed information about the spatial and temporal distribution of landslide movements within the study area. This approach is particularly useful for investigating highly hazardous landslides, which threaten exposed, built-up areas. In such situations, the assessment of the future evolution of slope instabilities by means of integrated monitoring systems plays a major role in the adequate set up of early warning systems (EWS) and emergency plans, fundamental tools for landslide hazard and risk reduction.

The SAFER services, which are part of the GMES (Global Monitoring for Environment and Security) initiative, are targeted at the integration of users (e.g., public authorities such as civil protection agencies, humanitarian aid organizations, NGOs), who are supposed to make use of the 
provided services and products in emergency situations. By expressing their explicit needs as well as proposing improvements through feedback questionnaires, the users support the deployment of an operational emergency response service. The user engaged in the LM monitoring service in the Mont de la Saxe area is the Italian Department of Civil Protection (DPC), the national institution in charge of risk management and mitigation over the whole Italian territory. The investigated area represents one of the most hazardous areas of the Valle d'Aosta Region due to widespread slope instability affecting very steep slopes overlooking narrow, but densely urbanized valleys and exposing local population and infrastructure at risk.

\subsection{OBIA for Landslide Mapping}

Today, the wide range of available Earth observation (EO) data implies the need for accurate and fast methods for detecting, analyzing and monitoring landslides and to facilitate the generation of landslide inventory maps and databases to assist hazard and risk analysis. Landslide inventories are traditionally derived by visual interpretation of aerial photographs and field surveys. This kind of inventory is, however, time-consuming, fraught with the subjectivity of the visual interpreters and very costly in terms of data and workload. Satellite imagery offers a fast and economical opportunity to monitor slopes and map landslides over large and inaccessible areas, especially since the spatial resolution is ever increasing [3-6]. Applying automated methods can contribute to more efficient monitoring and timesaving as well as cost-efficient updating of existing landslide inventories.

Supervised and unsupervised classification methods of multi-spectral SPOT-5 imagery for mapping landslides were successfully used by Borghuis et al. [7] and then compared to a manual delineation. Nicol and Wong [8] used a Maximum Likelihood classifier with SPOT XS images and were able to detect approximately $70 \%$ of the existing landslides. A multiple change detection (MCD) technique to semi-automatically recognize and map landslides triggered by typhoons has been developed by Mondini et al. [9]. However, in many cases object-based methods seem to capture the complexity of natural phenomena and geomorphologic processes such as landslides in a more appropriate way than traditional pixel-based ones [10]. Thus, salt-and-pepper effects are avoided, which is especially important when dealing with complex features in terms of shape and size as landslides, where pixels show quite different spectral values. Semi-automated methods for landslide detection and analysis, especially object-based image analysis (OBIA) techniques [11,12], although still not very common, are able to deliver fast and accurate results as demonstrated by several studies. An object-based approach using a combination of high spatial resolution satellite imagery and DEM derivatives has been proposed by Barlow et al. [3]. According to the classification scheme of Cruden and Varnes [13] they distinguished between debris slides, debris flows and rock slides and achieved accuracy rates between $60 \%$ for debris flows and $90 \%$ for debris slides. Barlow et al. [3] pointed out that per pixel spectral response patterns are ineffective for delineating mass movements and instead applied an image segmentation and classification approach combining high spatial resolution satellite imagery and digital elevation derivatives. Similar approaches were demonstrated by Lahousse et al. [14], who applied a multi-scale object-based landslide detection technique based on optical imagery supported by digital elevation information to map shallow landslides in Taiwan, or Martha et al. [10], who characterized landslides based on their spectral, spatial and morphometric properties, while Martha et al. [15] 
elaborated the objective selection of suitable segmentation parameters to outline landslides as individual segments for subsequent landslide classification. A supervised workflow based on a Random Forest machine learning algorithm was developed by Stumpf and Kerle [5] and successfully tested on various optical data sets reaching accuracies between $73 \%$ and $87 \%$. Further approaches for object-based landslide identification were shown by Martin and Franklin [16] for classifying soil and bedrock-dominated landslides in British Columbia, Moine et al. [17], who semi-automatically detected landslides in the French Alps using aerial and satellite images, Rau et al. [18] by using imagery acquired by a fixed-wing unmanned aerial vehicle (UAV), Hölbling and Füreder [19], who carried out preliminary work in the Aosta Valley, Northern Italy, distinguishing different mass movement types, or by Aksoy and Ercanoglu [20], who identified landslides on Landsat ETM+ (Enhanced Thematic Mapper Plus) imagery applying fuzzy classification. In the context of rapid landslide mapping a semi-automatic object-based change detection analysis was suggested by $\mathrm{Lu}$ et al. [4]. An automated classification system of morphological landform elements based on OBIA has been established by Drăgut and Blaschke [21]. Their approach focuses on the use of Digital Terrain Models (DTMs) and its derivatives and they were able to transfer the approach to different landscapes and datasets. A related object-based method was recently proposed by Drăgut and Eisank [22], who automatically classified topography from SRTM (Shuttle Radar Topography Mission) data to decompose land-surface complexity into homogeneous domains.

OBIA is making considerable progress towards a spatially explicit information extraction workflow [11] as it offers a methodological framework for addressing complex classes, defined by spectral, spatial and structural as well as hierarchical properties [23]. Thus, it provides suitable methods for analyzing landslides by using remote sensing data. Main assets of OBIA are the general potential to tackle the complexity and multi-scale characteristics of very high spatial resolution (VHSR) imagery and to allow the integration of various data sources $[11,12]$. Object-based methods have a high potential to monitor the evolution of landslide-prone areas over time, as spectral, spatial, contextual as well as morphological parameters can be considered [19]. In the present study the potential of an object-based landslide detection and classification approach is evaluated in an operational context aiming for the development of integrated solutions for mapping and monitoring landslides.

\section{Study Area and Data}

\subsection{Geological Characterization of the Study Area}

The study area 'Mont de la Saxe' is located in the Aosta Valley, North-Western Italy, near the Mont Blanc massif and covers approximately $70 \mathrm{~km}^{2}$ (see Figure 1). Major villages within the study area are Cormayeur and Entréves. The Dora Baltea river originates here as the confluence of Dora di Ferret and Dora di Vèny streams. The study area is characterized by steep terrain with altitudes ranging from approximately $1,100 \mathrm{~m}$ to over 4,000 $\mathrm{m}$ above sea level.

The Western Italian Alps constitute a collisional belt developed from the Cretaceous onwards by subduction of a Mesozoic ocean and continental crust of the Adriatic (Austroalpine-Southalpine) and European (Penninic-Helvetic) continental margins [24]. 
Figure 1. Overview of the study area Mont de la Saxe (SPOT-5 data within the red rectangle is displayed in false color composite, band combination 1-2-3, Acquisition Date: 5 May 2005).

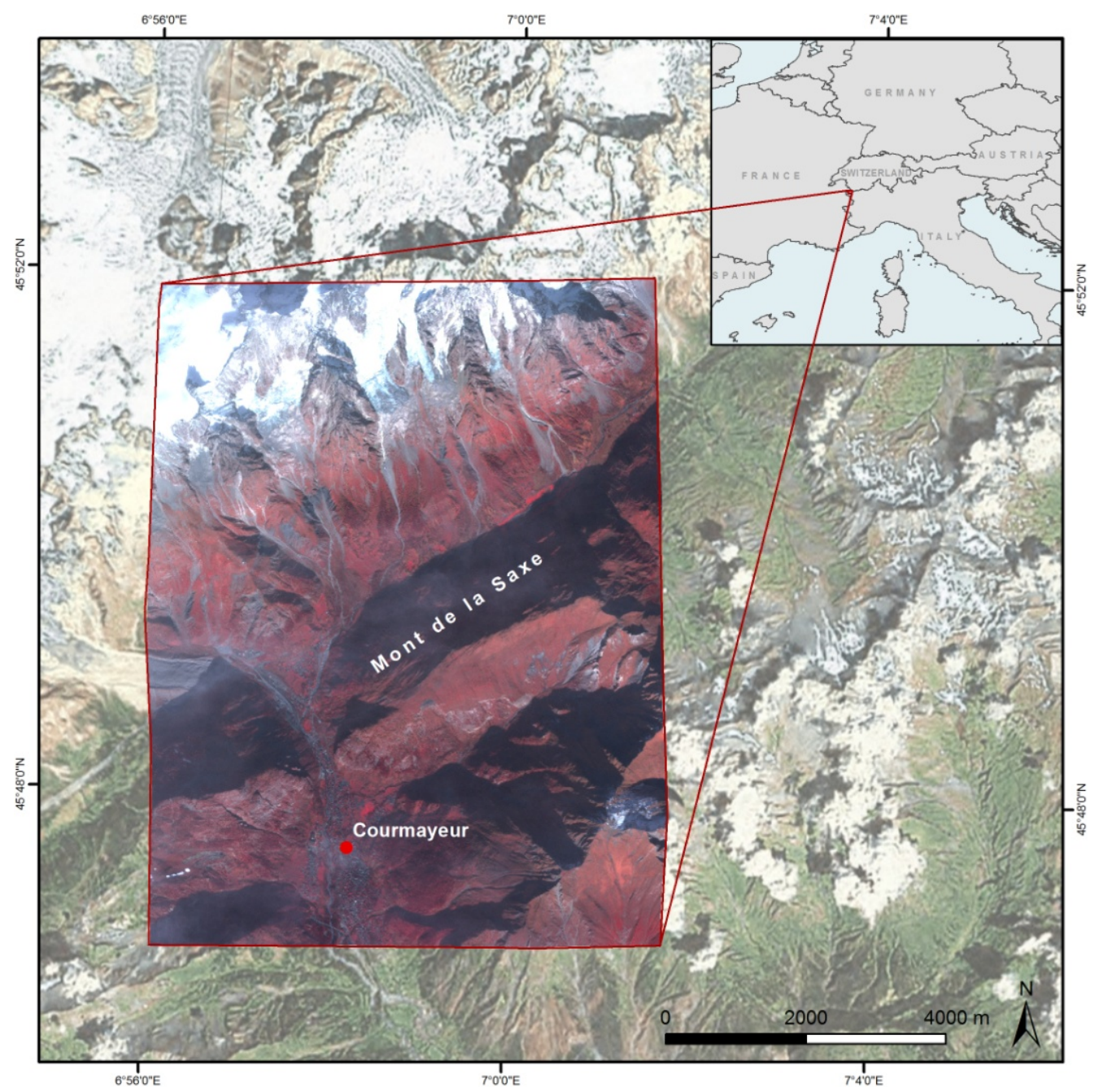

In the study area, from the external to the internal sectors, three main tectono-stratigraphic units crop out (Figure 2):

- Monte Bianco massif and Mont Chètif wedge complex, belonging to the Helvetic Domain, consist of paragneisses, migmatites, orthogneisses, granites and porphyries; in the SE part of the massif (Val Veny-Val Ferret) the contact with surrounding units is tectonic.

- Ultrahelvetic units, a meta-sedimentary sequence which predominantly consist of closely foliated carbonate-bearing argillaceous schists and arenaceous limestones with quartz arenites levels. The age of the sequence can be referred to as the Middle Jurassic.

Penninic units, which comprise the lower distal clastics and pelagic Cretaceous deposits of the Courmayeur Zone, the more internal ocean-continent transition zone (Valais zone) and the middle Penninic nappes consist of Zone Huillère Permo-Carboniferous deposits (black schist with coal measures, quartzites and conglomerates) and a Pre-Permian crystalline basement (paragneiss and micaschists with amphibolites and metabasites intercalations). The described units dip towards SE forming an imbricated structure, and are arranged as large belts oriented NE-SW. 
Quaternary alluvial, glacial and debris deposits directly lie unconformably and discontinuously on the bedrock. The recent and actual alluvial deposits rest on the valleys' bottom and consist of gravels, pebbles and boulders in coarse-grained sandy matrix along the river channels and finer-grained deposits (sandy silts and silts) in floodplain areas. Old glacial deposits crop out discontinuously along the slopes at elevations up to $2,000 \mathrm{~m}$ above sea level, while the recent ones become particularly widespread along secondary tributary valleys at higher altitudes. They consist of massive boulders, pebbles and gravels in an abundant sandy-silty matrix (diamicton). The debris deposits include talus, alluvial fan and flow deposits and crop out at the base of rocky cliffs (talus), along the stream incision (flow deposits) and at the outlet of the minor valleys (alluvial fans).

Figure 2. Geologic and structural sketch of the study area. Modified from Carta Geologica d'Italia 1:100,000, Sheets 27-28.
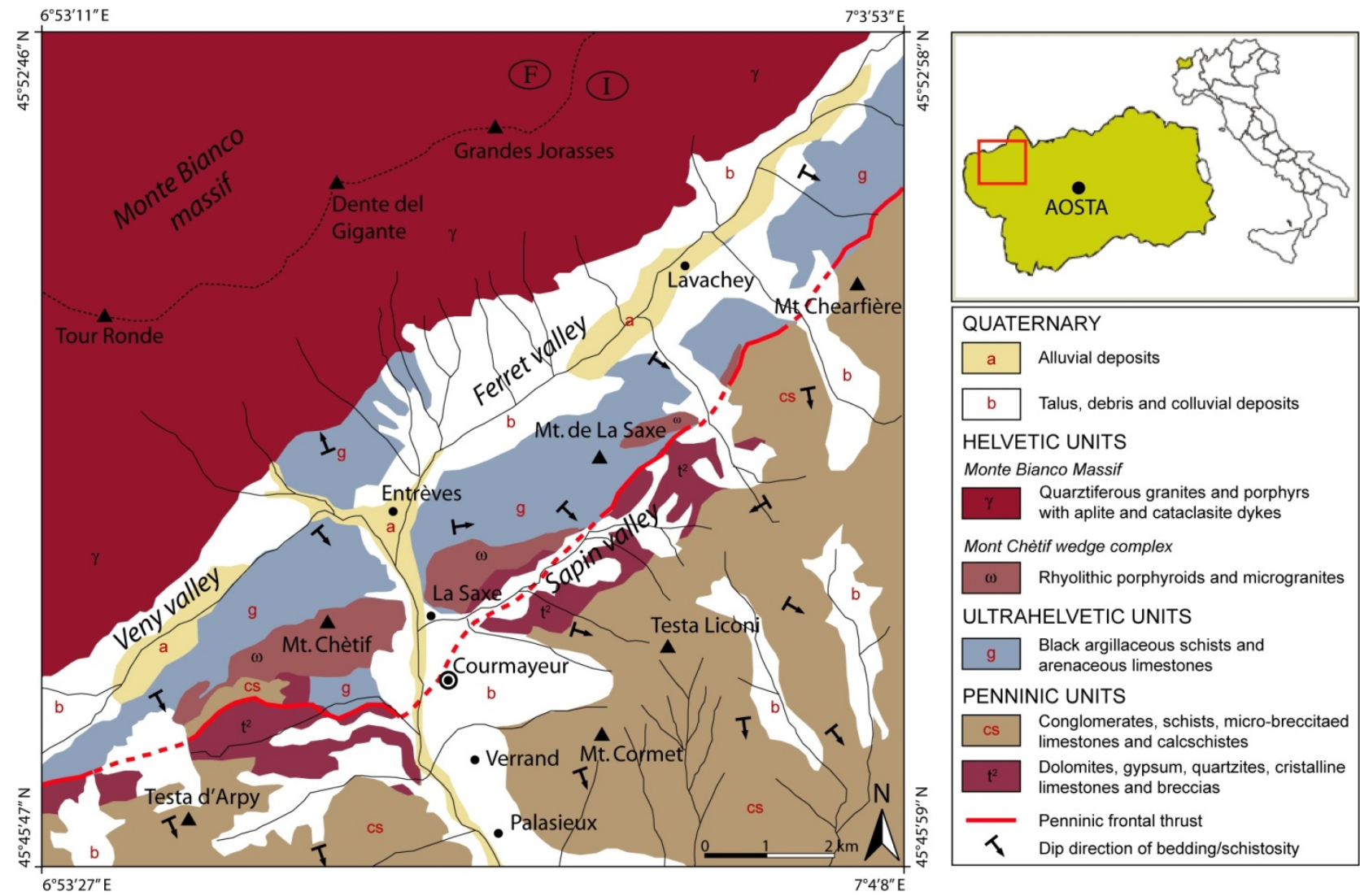

The structural setting of the study area is strictly influenced by the Penninic frontal thrust and the Ultrahelvetic front, two regional compressive structures oriented NE-SW which separate the main tectono-stratigraphic units previously described. These lineaments are associated with secondary shear planes, milonitic and cataclastic bands, further complicating the structural setting of the area. In particular, the Penninic frontal thrust is a tectonic alignment of regional importance and its presence is detectable along most of the Western Alps [25-27].

Due to the general high relief energy and the steep slope gradient, slope instability is quite diffused in the study area. There is a clear relationship between the material involved in the instability and development of a particular type of movement. Rock falls and topples, resulting in formation of wide talus deposits are, in general, widespread along the steep rocky slopes and cliffs characterized by the presence of fractured hard rock mass (granites, gneiss, porphyries, quartzites). In some cases complex 
large falls (i.e., rock avalanches) have been reported [28]. Deep-seated large landslides affect high steep slopes shaped in metamorphic rocks with marked anisotropy such as gneiss and schists of the Ultrahelvetic and Penninic units. Within the displaced mass the development of sudden and rapid secondary landslides (topples, rotational and planar slides, and flow-like movements) is a common feature, giving rise to complex deformational patterns. Shallow landslides and channelized flows affect in general colluviums, weathered bedrock, soils and the more erodible lithologies of the Ultrahelvetic and Penninic units, such as argillaceous schists and black schists with coal measures (Zone Houillère). In some cases, movements could be initialized by sliding on the bedding or schistosity planes and then evolve as flow-like phenomena, thus generating complex landslides.

The Mont de la Saxe is affected by the Bois de Plan Cereux landslide (Figure 3), which constitutes an active portion of a large deep-seated gravitational slope deformation (DSGSD) extending along the whole Mont de la Saxe ridge. The instability, which can be classified as a complex landslide [13] with an estimated volume of a few $\mathrm{Mm}^{3}$, involves a significant portion of the slope and poses high risk to the Entrèves and La Palud villages as well as to the infrastructure (i.e., A5 motorway, SS26 national road, Monte Bianco cableway). The SE slope of the Mont de la Saxe ridge (Val Sapin) is characterized by the presence of complex and planar/rotational slides.

Figure 3. Frontal view of the Mont de la Saxe deep-seated gravitational slope deformation (DSGSD) showing the Bois du Plan Cereux active landslide and the Bois du Point Pailler dormant landslide.

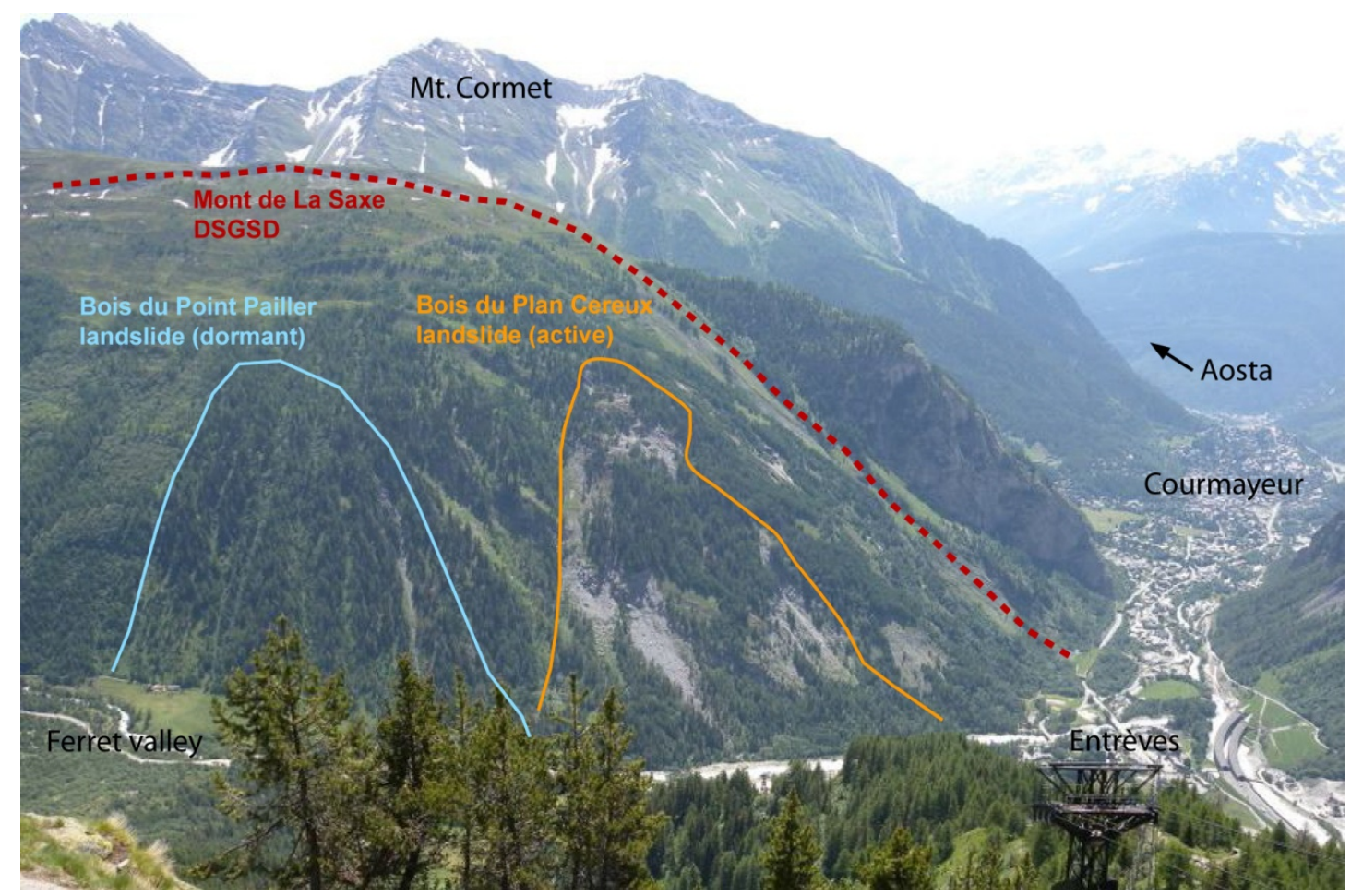

\subsection{Data}

The object-based detection of landslides was based on optical, very high spatial resolution satellite imagery (SPOT-5, acquisition date: 5 May 2005) and digital elevation data (DEM with 20 m GSD) including its derived products slope, aspect, curvature and plan curvature. The multispectral SPOT-5 
image with two bands in the visible spectrum (red, green) and a near infrared (NIR) band was available in pan-sharpened mode with a spatial resolution of $2.5 \mathrm{~m}$. Although the satellite image was supplied in geo-referenced format, it had to be co-registered to remove distortions between the SPOT-5 image and available orthophotos, which were used as reference for the visual interpretation of the PSI results. Due to the steep terrain features within the study area, some mountain sides, including the northern hillside of Mont de la Saxe, are shaded on the SPOT-5 image and could not be taken into account for the classification.

The DEM showed some gaps and data errors, which had to be corrected before integrating it in the further analysis. Single DEM tiles were mosaicked and false values adjusted taking into account neighborhood statistics calculated for each affected input cell using map algebra in ArcGIS 10 software. The following morphological parameters were derived from the DEM to support the object-based classification of landslides: slope, aspect, curvature and plan curvature. A low pass 3-by-3 filter was applied to the curvature derivative to generate a smoother layer with less noise.

Data used for validating results of the object-based image analysis included the Italian national landslides inventory: IFFI (Inventario dei Fenomeni Franosi in Italia), and the Hydrogeological Asset Plan: PAI (Piano Stralcio per l'Assetto Idrogeologico) of the Po River Basin Authority. In addition, datasets of persistent scatterers (PS) were obtained by the processing of satellite SAR (Synthetic Aperture Radar) data acquired by three different C-band satellites (wavelength of $5.6 \mathrm{~cm}$ ) along both ascending and descending orbits, and using monthly temporal frequency. ERS1/2 data acquired in ascending mode from 11/06/1993 to 25/12/2000, and in descending mode from 17/04/1992 to 25/12/2000 with a nominal repeat cycle of $35 \mathrm{~d}$ and ENVISAT ASAR (Advanced SAR) and RADARSAT-1 scenes with 35 and $24 \mathrm{~d}$ repeat cycle were used. ENVISAT ascending and descending data cover the intervals from 07/06/2004 to 19/10/2009 and 20/09/2004 to 23/11/2009, while RADARSAT-1 ascending and descending images span the intervals from 05/05/2006 to 28/10/2009 and $25 / 08 / 2005$ to $15 / 10 / 2009$. These data were processed by Altamira Information with the Stable Point Network (SPN) technique [29,30].

\section{Methodology}

\subsection{Object-Based Class Modeling}

The distinction of the two classes flow-like landslides and other landslide types (falls, topples, slides and spreads) follows the kinematic-based classification of Cruden and Varnes [13]. Within the study area the class flow-like landslides mainly covers channelized debris bodies and their depositional areas. The source areas of the flows are included in the class other landslide types since the movements very often initiate at the head of the stream incisions by sliding or by concentrate erosion. The detection of flow-like landslides and other landslide types was conducted by applying object-based image analysis in eCognition 8 software, which offers a modular programming environment for (image-)object handling in a vertical and horizontal hierarchy [31]. Rulesets for automated analysis are coded in CNL (Cognition Network Language) within the mentioned software. OBIA constitutes the methodological framework for machine-based interpretation of target features defined by spectral, spatial, structural, contextual and also hierarchical properties [23], while reducing the influence of per pixel spectral 
response patterns. Knowledge is represented through the use of rule-based classifiers, making explicit the required spectral and geometrical properties just as spatial relationships for advanced class modeling [32]. Class modeling, a cyclic process of segmentation and classification, allows addressing objects individually in a region-specific manner at any stage in the ruleset [32].

\subsection{Estimation of Appropriate Scale Parameter}

In order to objectively select a suitable scale parameter for the appropriate image segmentation a statistical tool called ESP (estimation of scale parameter), developed by Drăguţ et al. [33], was used. The ESP tool iteratively generates image-objects at multiple scale levels in a bottom-up approach and calculates the local variance of object heterogeneity within a scene for each scale [33]. By plotting the local variance against the respective scale the variation in heterogeneity can be evaluated. The scale levels at which the image can be segmented in the most appropriate manner, relative to the data properties at the scene level, are indicated by the thresholds in rates of change of local variance $(R O C-L V)$ [33]. Based on this evaluation a scale parameter of 36, indicated by a peak in the ROC-LV graph (see Figure 4), was chosen for the initial multi-resolution segmentation.

Figure 4. Results of the estimation of scale parameter (ESP) analysis showing potential scales for image segmentation. The peaks in the Rate of Change graph indicate object levels at which the image can be segmented in an appropriate manner (here a scale parameter of 36 was found suitable).

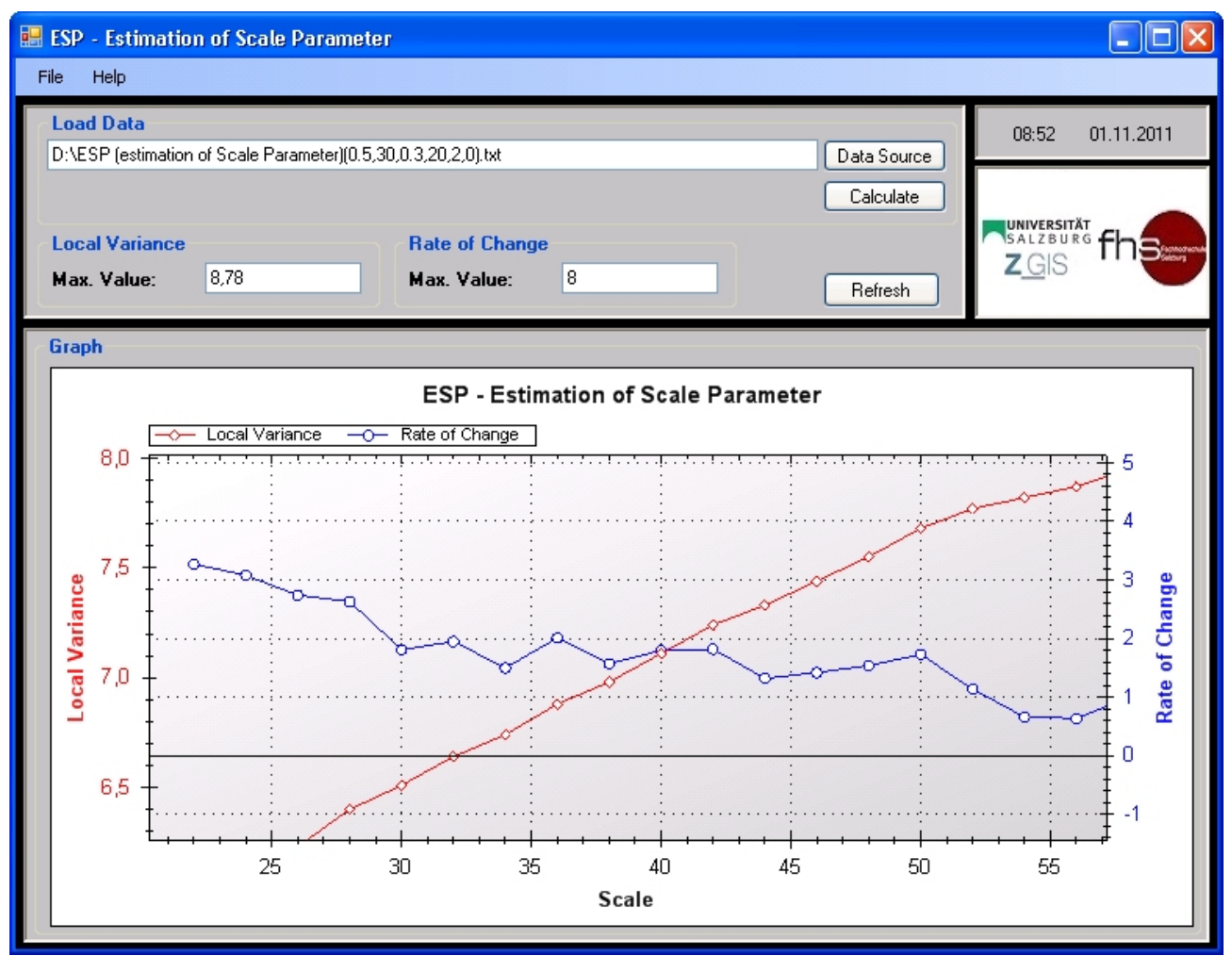

The three multispectral bands of the SPOT-5 image were used for segmentation. A higher weight was given to the color criterion than to the shape criterion. A coarser segmentation level with scale parameter 82 and the same shape (0.3) and compactness factors (0.5) as for the finer segmentation 
level, also determined by making use of the ESP tool, resulting in larger image-objects, was created to facilitate a first, rough delineation of target areas affected by landslides.

\subsection{Rule-Based Classification}

By using OBIA, the influence of variant spectral reflectance of single pixels can be minimized. This seems to be applicable especially for natural, complex phenomena such as landslides, which tend to exhibit varying spectral response patterns. The creation of rulesets relied on the transformation of expert knowledge into machine-based rules, whereby the SPOT-5 image constituted the a priori data used for landslide detection and classification. During class modeling absolute spectral threshold values were kept to a minimum, whereas relational features and spatial characteristics were used instead. Vegetation indices as the NDVI (Normalized Difference Vegetation Index) and the MSAVI (Modified Soil-Adjusted Vegetation Index, see Equation (1)) proved to be very useful for differentiating target areas from areas of no interest.

$$
M S A V I=\frac{2 * N I R+1-\sqrt{(2 * N I R+1)^{2}-8(N I R-R E D)}}{2}
$$

where NIR is the near infrared band and RED the red band.

As a first step, potential landslides were identified as target objects on the finer segmentation level by applying the mentioned vegetation indices in combination with other feature characteristics, for example slope, standard deviation of the near infrared band, the maximum spectral difference within image-objects, neighborhood information, shape properties (e.g., length/width) or relief, the maximum change in elevation within an object. Objects with slope gradients above 60 degrees and below 10 degrees were excluded from the target objects. The range of these thresholds was defined relatively wide, but should ensure not to miss any areas of interest. Additionally, aspect, curvature and plan curvature appeared to be appropriate for improving the detection of target areas. By making use of these characteristics it was possible to exclude falsely classified target areas, for example rocky ridges in high-lying areas, as well as add some missed objects. The pre-classified objects were further divided into two classes: flow-like landslides and other landslide types. As the segmentation levels follow a strict image-object hierarchy the initial classification of target areas on the finer level could be transferred to the level above. The differentiation of classes was initially done on the coarse segmentation level, where shape parameters in particular, but also morphological characteristics appeared to be more significant for a first, rough separation than on the fine segmentation level ( $c f$. Figure 5). Mainly the mean slope was used to distinguish flow-like landslides from other landslide types. Image-objects with a mean slope higher than $25^{\circ}$ were allocated to the class other landslide types, those with a lower value were classified as flow-like landslides. Besides slope, also aspect, curvature and plan curvature were used for this first differentiation. Latter mentioned morphological characteristics turned out to be useful for supporting the class separation on the coarse segmentation level (e.g., low plan curvature values were considered for the detection of flow-like channelized landslides), but as the spatial resolution of the available DEM (20 m GSD) was not fully sufficient for determining unique thresholds, they were mainly used in combination with shape characteristics such as length/width or the brightness of objects (flow-like landslides tend to appear brighter on the SPOT-5 image) to facilitate the stepwise refinement of the classification. 
Figure 5. Workflow for the semi-automated detection of flow-like landslides and other landslide types in an object-based environment.

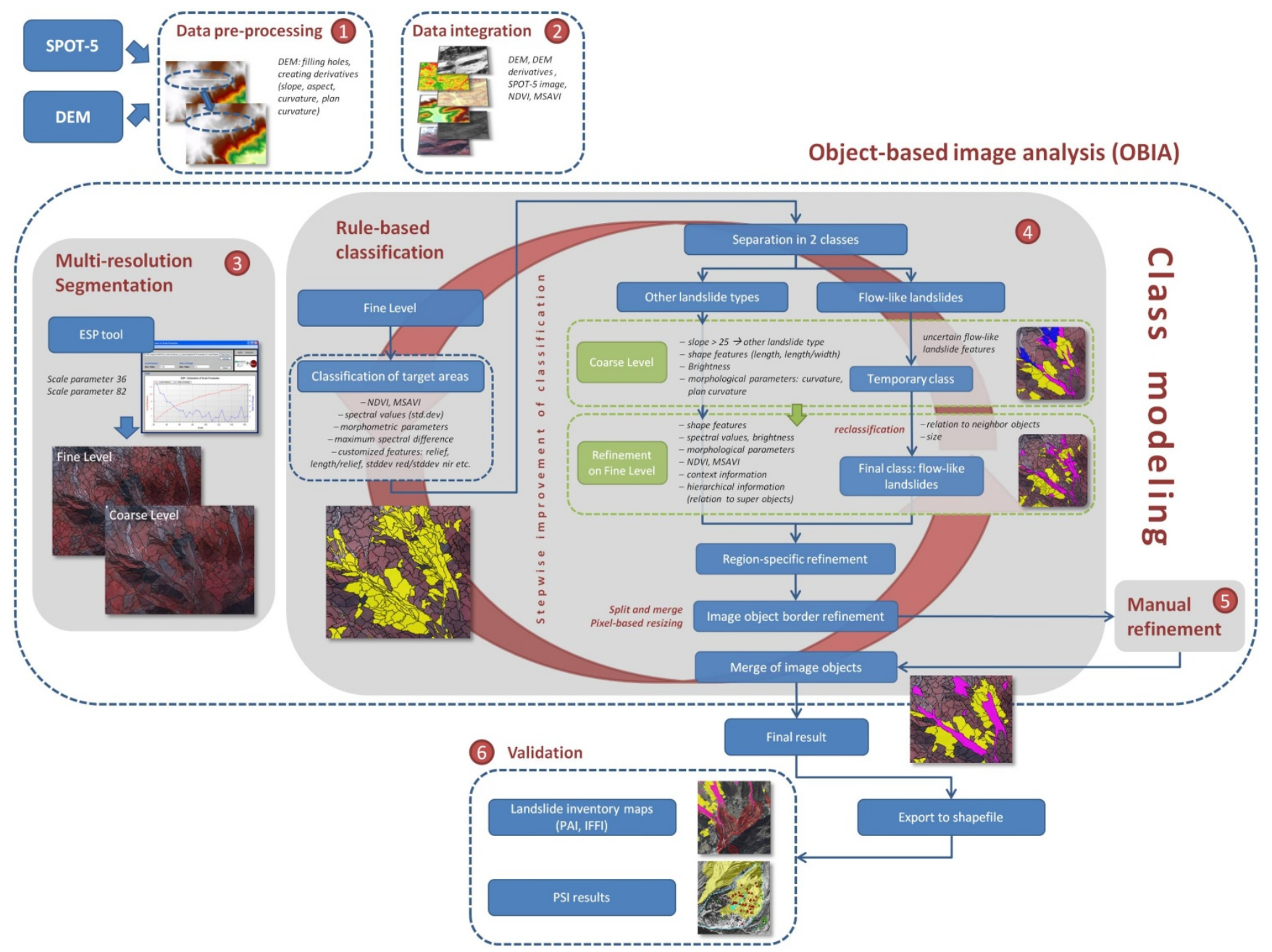

Subsequently, the intermediate classification results were transferred to the finer segmentation level for further improvement of the classification. The refinement of the classification comprised the use of selected feature characteristics: besides the NDVI, spectral and spatial properties (length/width or compactness), morphological parameters as aspect and slope and especially context information (e.g., relative common border to neighboring objects) and hierarchical information (relations to super objects on the higher segmentation level) were taken into account. As natural phenomena like landslides can hardly be described using one absolute threshold, several image-object feature characteristics combined with context information were used for the further improvement of the classification. For instance, if objects were primarily classified as flow-like landslides, but their classification was fraught with uncertainty and the objects only slightly missed the parameter thresholds attached to the class other landslide types, they were assigned to a temporary class in the first step. Secondly, if these temporary objects, which were most often relatively small ones, showed a high relative border to the class other landslide types or were almost completely enclosed by this class, they were finally reclassified as other landslides type. Using neighborhood characteristics, in this case the relative border to neighboring objects, contributed essentially to the improvement of the classification. 


\subsection{Region-Specific Refinement}

In a few areas (e.g., partially shadowed regions on the SPOT-5 image) some misclassifications still occurred. In such cases, we made use of the capability of eCognition software to address specific regions individually. Thereby it is possible to adapt certain rules only to pre-defined regions within a larger study area. This allows for more detail and quickly eliminates classification errors and also reduces analysis time as it is not necessary to find valid rules for the whole area under investigation.

\subsection{Image-Object Border Refinement for Deriving Meaningful Image-Objects}

Finally, the delineation of 'meaningful' image-objects was further enhanced through applying split and merge functions as well as smoothing of image-object boundaries by using pixel-based resizing algorithms. In order to keep the preliminary existing result, the refinement of the boundaries was done on an independent segmentation and classification layer. Working with such sub-projects in one eCognition project allows running processes independently, for example performing independent segmentation and classification while not changing the initial image-object borders.

For smoothing the boundaries of classified objects, specific pixel-based shrinking algorithms were applied. Edge pixels between flow-like landslides and other landslide types with an NDVI value below 0.1 were allocated to a temporary class applying a surface tension of larger than 0.4 within a $5 \times 5$ pixel window. Surface tension is calculated based on the relative area of a given class within a moving window around the current candidate pixel. The ratio of the relative area of seed pixels to all pixels inside the moving window is computed [34]. The temporary image-objects were subsequently merged to those neighboring objects with the highest relative common border. Consequently, smoother borders between flow-like landslides and other landslide types were achieved (Figure 6). Further shrinking was done for edge pixels between classified landslide objects with NDVI values higher than 0.2 and unclassified objects, keeping the same size of the moving window, but increasing the surface tension value to 0.5 .

Figure 6. Pixel-based resizing of object boundaries. Black ellipses highlight examples for edge pixels between flow-like landslides and other landslide types; red ellipses highlight examples for edge pixels between classified objects and unclassified objects. (a) Classified objects before pixel-based resizing. (b) Temporary image-objects are displayed in blue color. (c) Result with smoother boundaries after applying pixel-based resizing.
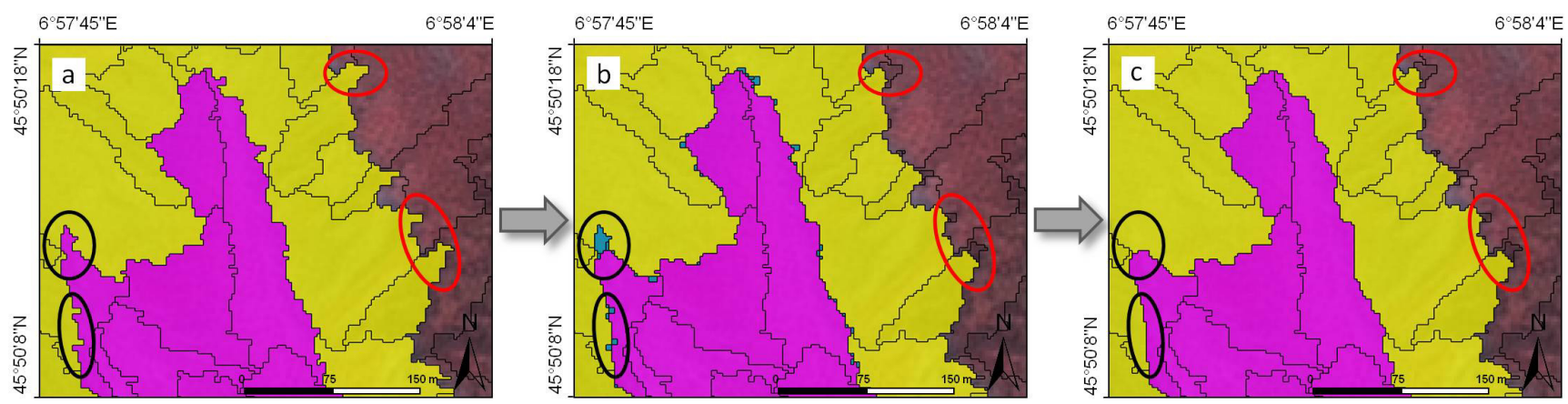
As one of the last refinement steps, classified image-objects smaller than $200 \mathrm{~m}^{2}$, having no common border to other classified objects, were removed, and unclassified objects smaller than $300 \mathrm{~m}^{2}$, which were enclosed by flow-like landslides or other landslide types, were assigned to the respective enclosing class. While a few objects, which probably constituted objects of interest, still remained unclassified and some others seemed to be assigned to the wrong class, a minimal manual refinement was done at this stage. As this affected only a minor number of small objects it was decided to perform a manual improvement instead of applying additional rules.

Finally, the classified objects were partly merged to obtain more 'meaningful' objects. Therefore, several rules, considering aspect, size or maximum change of slope, were used to ensure that not all objects of one class were merged, but rather the most similar ones, which ideally represent one landslide.

\section{Results and Discussion}

\subsection{Results of Object-Based Landslide Detection}

The result of the object-based landslide detection for the Mont de la Saxe study area, which covers approximately $70 \mathrm{~km}^{2}$, is shown in Figure 7. In total, an area of $3.77 \mathrm{~km}^{2}$ was classified as landslide-affected; comprising an area of $1.68 \mathrm{~km}^{2}$ flow-like landslides (mainly channelized debris bodies and their depositional areas) and $2.09 \mathrm{~km}^{2}$ classified as other landslide types (falls, topples, slides and spreads). The smallest other landslide type detected is $556 \mathrm{~m}^{2}$, the largest $94,500 \mathrm{~m}^{2}$; the smallest and largest flow-like landslides are $1,800 \mathrm{~m}^{2}$ and $262,000 \mathrm{~m}^{2}$, respectively.

Due to the illumination conditions at the acquisition time and the orientation of the mountainous ridges and valleys (NE-SW), all slopes facing towards NW resulted in shadowed areas (see Figure 7). For these areas, it was hardly possible to detect all landslides on the basis of the optical satellite image. Other than these obstacles, minor errors of omission (i.e., a few small landslides or sub-areas of landslide complexes could not be detected) and commission (i.e., wrongly classified parts) occurred (see Figure 8). To correct these errors minor manual editing was conducted.

\subsection{Validation}

\subsubsection{Cross-Comparison with Pre-Existing Landslide Inventories}

In order to validate the detected flow-like landslides and other landslide types, the areas (i.e., classified image-objects) recognised as affected by instability processes, were compared with the Italian national landslides inventory: IFFI, and the Hydrogeological Asset Plan: PAI of the Po River Basin Authority.

Concerning the IFFI inventory (Figure 9(a)), the database, updated to 2007, was created by integrating a collection of historical and archive data, manual aerial photo interpretation, field surveys and detailed mapping. For every landslide a minimum datasheet indicating the localization, the type of movement and the state of activity is reported. The distinction of different types of movement is mostly based on the classification proposed by Varnes [35] and Cruden and Varnes [13] with some modifications. In particular, some types of movements (deep-seated gravitational slope deformations, 
areas affected by numerous falls/topples, numerous sinkholes or numerous shallow landslides) have been introduced, which, even limited in size, are widespread along certain slopes or affect very large areas [36]. In addition, the IFFI inventory also includes linear instability phenomena and limited areal phenomena displayed as point features.

Figure 7. Result of the object-based landslide detection based on the SPOT-5 imagery (acquisition date: 5 May 2005, false color composite). Pink areas represent flow-like landslides and yellow areas indicate other landslide types.

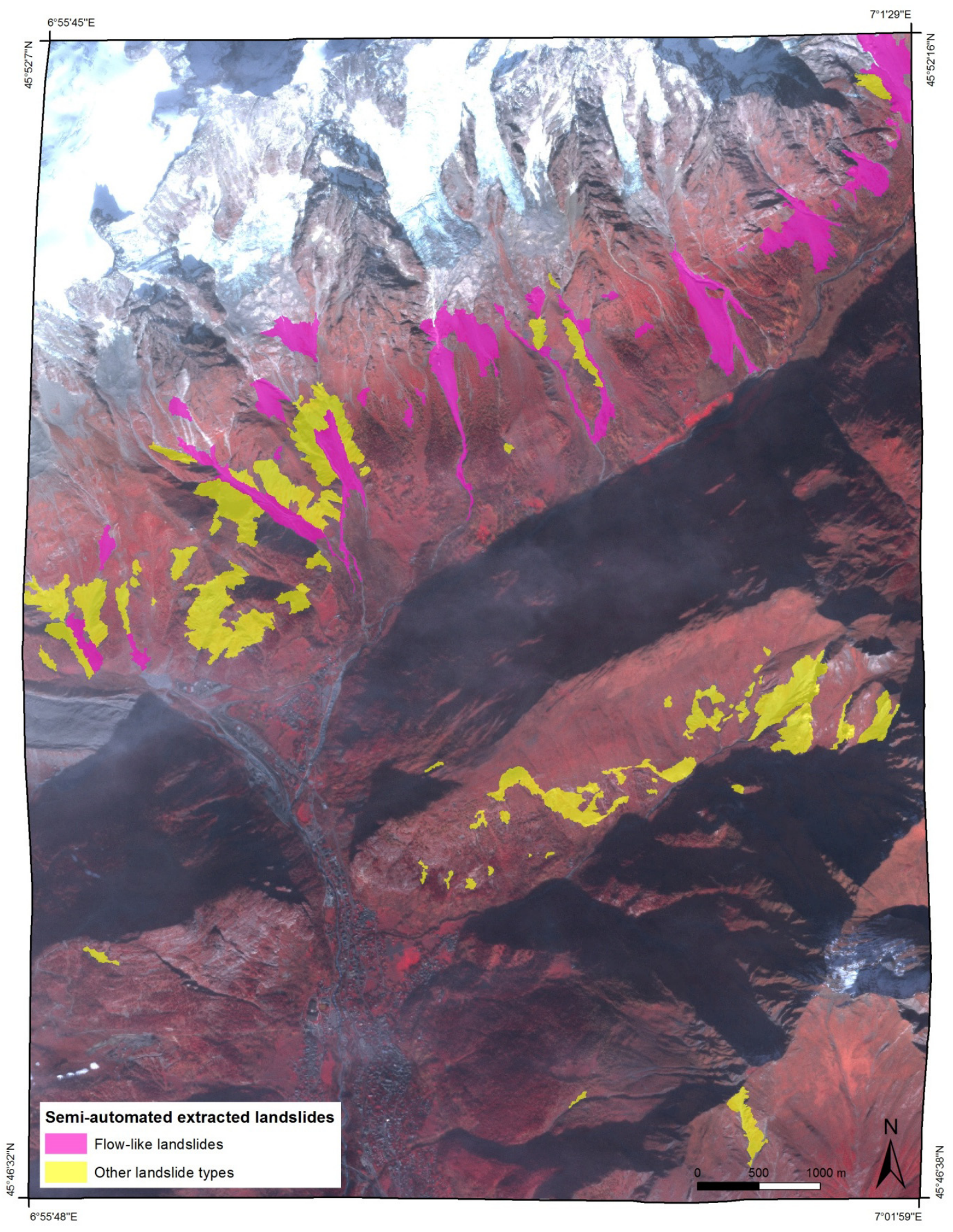


Figure 8. (a) Results of the object-based landslide detection showing (b) wrongly classified other landslide types (white outline) and (c) and (d) other landslide types, which were missed (black outline).
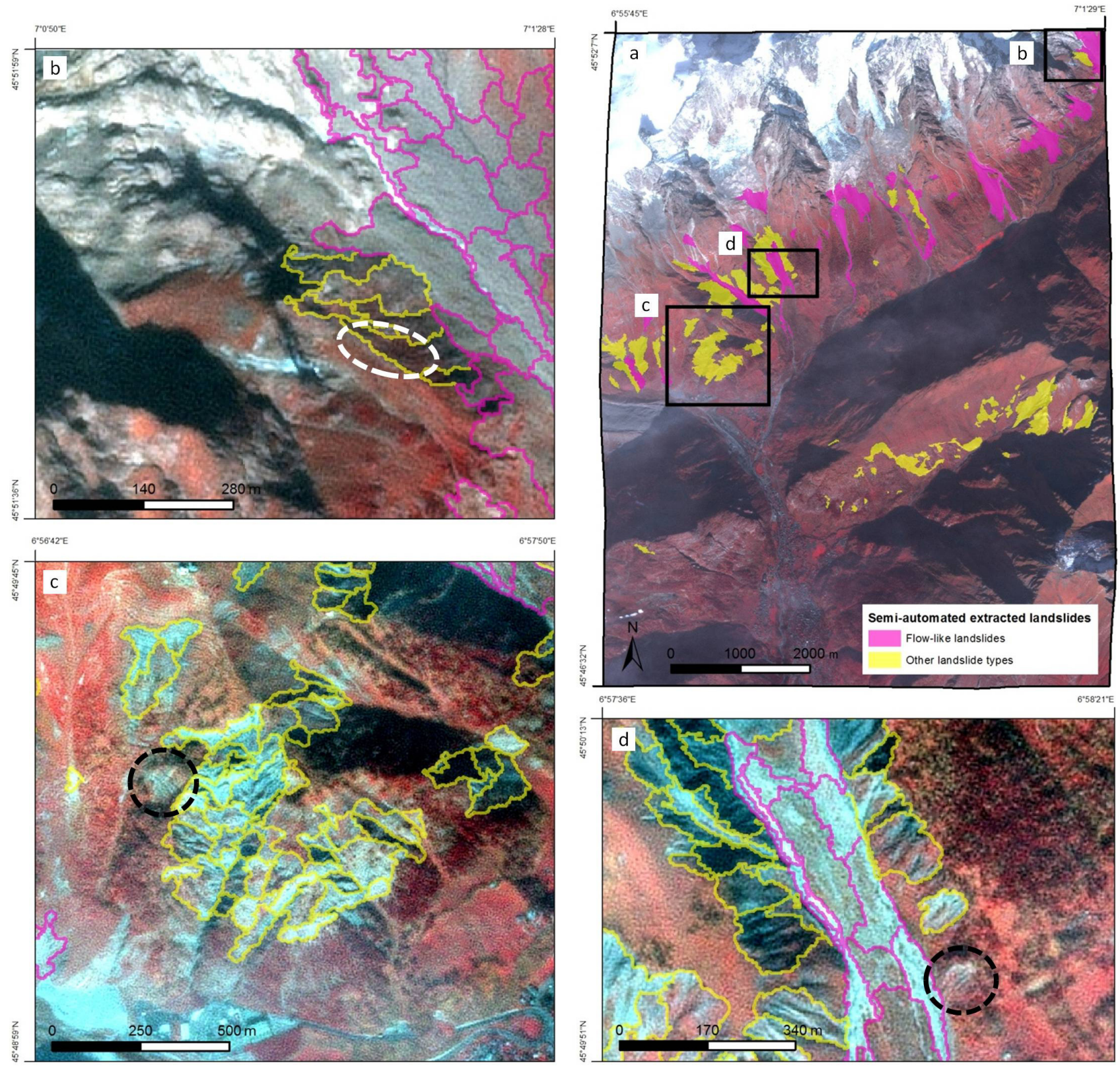

The main objective of the Hydrogeological Asset Plan (PAI, Figure 9(b)) is the reduction of the hydrogeological risk to ensure the safety of people and to minimize the threat to the exposed elements at risk. In Italy the Environmental Protection Law 183/1989 identified hydrographic basins as the optimal physical environment for land management in terms of risk limitation. The study area of Mont de la Saxe lies in the northern sector of the Po river hydrographic basin, the major Italian river basin with a total surface of about $74,000 \mathrm{~km}^{2}$. In this context, the areas characterized by higher landslide risk (R3 and R4 classes) were taken into account for validating the result of the object-based approach. The PAI maps have been updated to 2006 and also served as archive data for the realization of the IFFI database. 
Figure 9. Hillshade of the study area showing (a) the IFFI landslide inventory and (b) the $\mathrm{R} 3 / \mathrm{R} 4$ risk areas as reported in the Hydrogeological Asset Plan PAI.
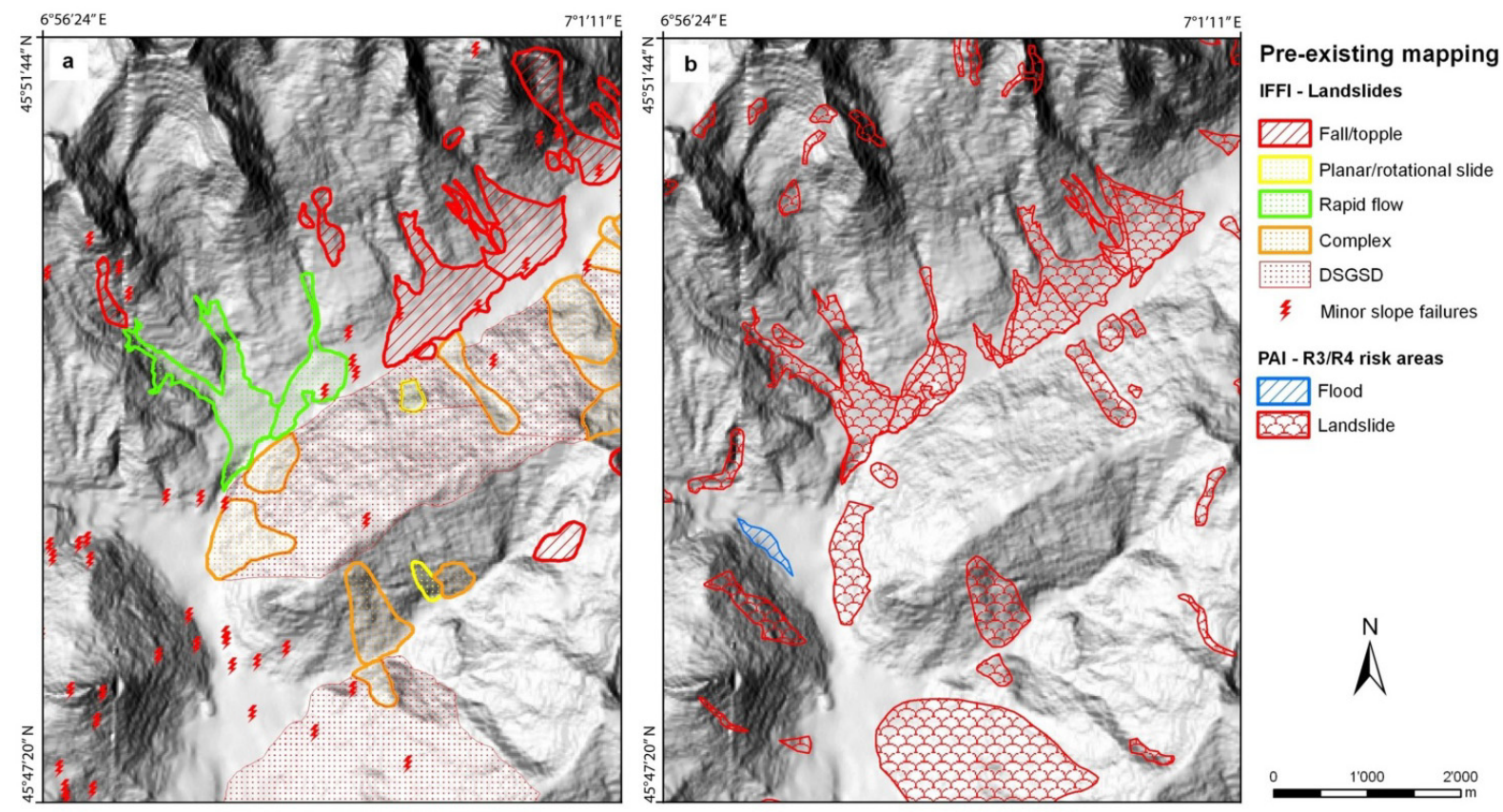

Table 1. Number of features and area of the landslides included in IFFI and PAI inventories compared to the results of the object-based image analysis.

\begin{tabular}{lll}
\hline OBIA & No of Features & Area $\left[\mathbf{k m}^{2}\right]$ \\
\hline Flow-like landslides & 275 & 1.68 \\
Other landslide types & 357 & 2.09 \\
Total & $\mathbf{6 3 2}$ & $\mathbf{3 . 7 7}$ \\
Spatial overlap with IFFI & & \\
Flow-like landslides & 181 & 1.16 \\
Other landslide types & 89 & 0.53 \\
Total & $\mathbf{2 7 0}$ & $\mathbf{1 . 6 9}$ \\
Spatial overlap with PAI & & \\
Flow-like landslides & 178 & 1.16 \\
Other landslide types & 104 & 0.74 \\
Total & $\mathbf{2 8 2}$ & $\mathbf{1 . 9 0}$ \\
IFFI & & \\
Fall/topple & 15 & 2.83 \\
Planar/rotation slide & 2 & 0.14 \\
Rapid flow & 2 & 1.18 \\
Complex & 12 & 3.18 \\
DSGSD & 6 & 10.79 \\
Total & $\mathbf{3 7}$ & $\mathbf{1 8 . 1 2}$ \\
PAI & & 12.26 \\
R3 and R4 areas & 50 & \\
\hline
\end{tabular}

In Table 1 the extension of the areas recognized as unstable by the object-based image analysis approach and the areas affected by landslides reported in the IFFI inventory and in the PAI are shown. 
It is worth noting that $92.9 \%$ of the high risk areas (in terms of $\mathrm{km}^{2}$ ) reported in the $P A I$ are also included in the IFFI database. For this comparison and further validation, not the result with the merged objects was used, but the objects showing the borders before the final merge instead. By using these smaller objects more detailed comparative statements can be made regarding the coincidence of specific objects with reference data sets.

An area of $3.77 \mathrm{~km}^{2}$ has been recognized as affected by landslides by the object-based approach. Approximately $44.8 \%$ (i.e., $1.69 \mathrm{~km}^{2}$ ) of the detected landslides are also classified areas of the IFFI inventory and about $50.4 \%$ (i.e., $1.9 \mathrm{~km}^{2}$ ) spatially overlap with the $\mathrm{R} 3$ and $\mathrm{R} 4$ areas of the PAI map. The marked differences in terms of total surface affected by slope instability between OBIA and the ancillary inventories are mainly due to the fact that the densely vegetated areas in the lower slope portions, where IFFI and PAI report a considerable amount of landslides, prevented a complete extraction of the landslide features with the available data ( $c f$. Figure 10(a,b)). Moreover, it was not possible to carry out the semi-automated analysis on the whole study area due to illumination conditions. On the other hand, in high, mountainous areas with limited accessibility (i.e., areas generally without element at risk) the IFFI and PAI maps are not completed and/or updated on a regular basis and show fewer landslides than detected through OBIA. In general, it has to be mentioned that these existing inventories, although officially used, cannot provide the 'true' reference as the delineation of affected areas is rather coarse and partly incomplete.

Further slight differences between the OBIA results and the pre-existing inventories can be attributed to the fact that the SPOT-5 image used in the analysis was acquired in 2005 while PAI and IFFI landslide maps are updated to 2006 and 2007, respectively.

In particular, taking into account the type of movement as indicated in the landslide inventory, the object-based approach was more effective in the detection of flow-like channelized landslides and areas affected by diffuse falls and topples. The major concentration of unstable areas is located in the SE slopes of the Monte Bianco massif (Ferret valley) and along the SE slopes of Mont de la Saxe ridge (Sapin valley).

In the lower Ferret valley (Figure 10(a,b)) many features detected by OBIA are located along the boundaries of the classified IFFI and PAI flow-like or falls/topples landslide bodies. In this case, it should be noted that $I F F I$ inventory tends to classify only the channelized debris bodies in the valleys and the depositional areas in the alluvial fans and talus as areas affected by flows or landslides. The OBIA approach instead allowed the identification of the source areas of the flows, located in the upper portion of the catchment basins. It is well-known that these areas can undergo very fast modifications following rainfalls and snow melting resulting in a retrogressive extension of the instability at the head of the river catchments. Concentrated erosion (gully erosion) is the typical process which causes the extension of the instability in the direction opposite the movement of the displaced material and preferably affects the erodible lithologies, such as the argillaceous schists of the Ultrahelvetic units and the detritic cover. 
Figure 10. Comparison of OBIA results, (a) IFFI and (b) PAI maps in the lower Ferret valley.
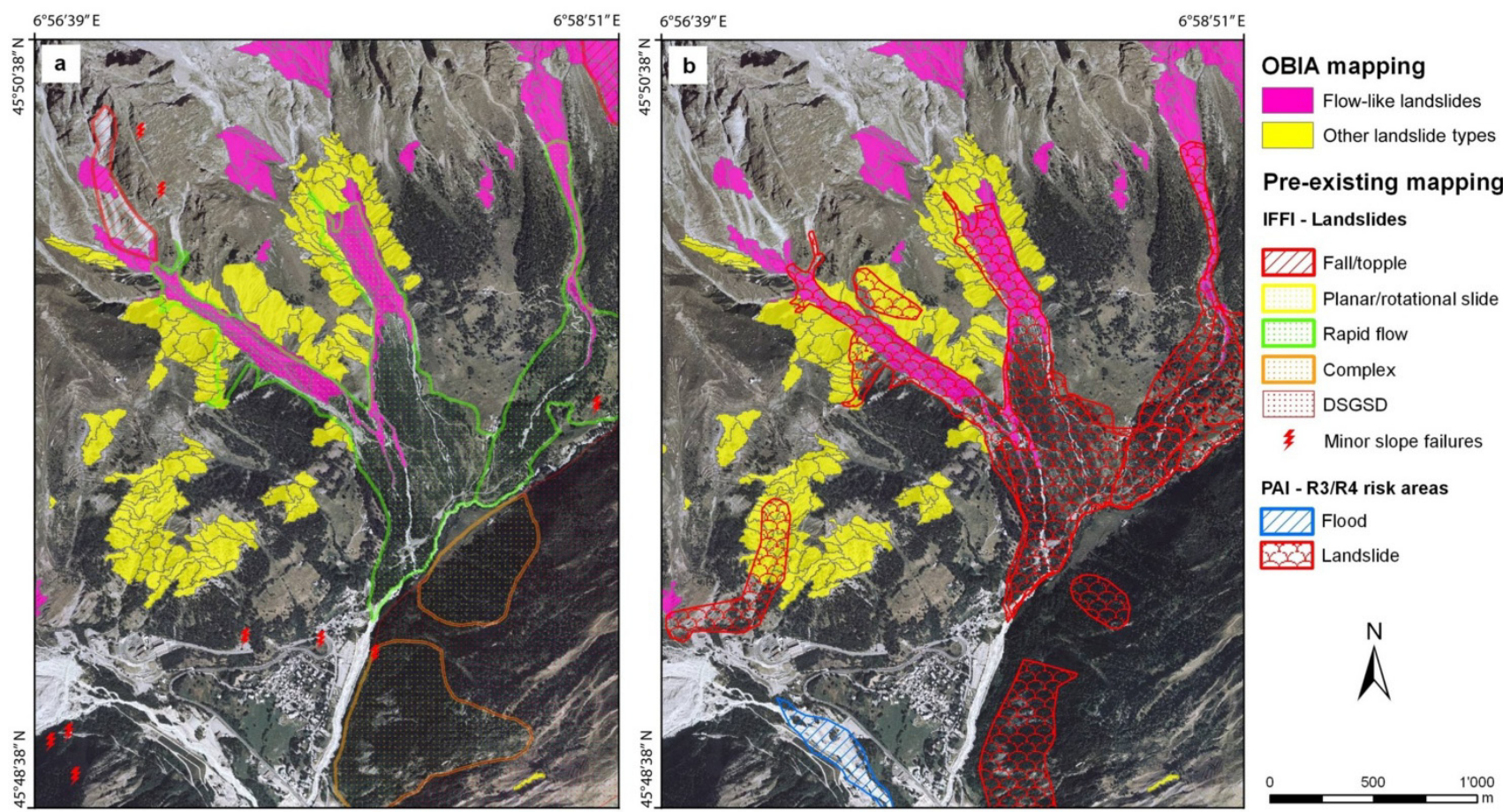

Another important geological consideration is that the IFFI classification of the instability phenomena along the SE slopes of the Monte Bianco massif is just a schematization and all landslides should be considered as complex. In fact, the upper portion of the slopes, constituted by hard rocks (granites, orthogneiss, migmatites), is characterized by diffuse falls and topples. The mobilized material is able to reach the valley's bottom in some cases, but more often it accumulates as talus and scree deposits along the slope. It can be subsequently mobilized and channelized as debris flows or debris slide during rainfall events. Therefore, all fan-shaped deposits along the Ferret valley should be considered as mixed alluvial fans-talus depositional systems. Hence, in this area the distinction between flow-like landslides and other landslide types can be considered subtle since talus and scree deposits can subsequently be mobilized as landslides.

The Bois de Plan Cereux landslide ( $c f$. Figure 3) was not detected by the OBIA methodology as its area was affected by shadowing at the time of the SPOT- 5 acquisition, and hence the landslide was not visible to the optical satellite.

Figure 11 shows that the object-based methodology allowed to identify the whole detachment area of a large slide in the upper part of the Sapin valley (Figure 11(a)) and to extend the unstable sectors towards NE. Comparing the IFFI and PAI maps, the landslide boundaries are not coincident, but the PSI analysis confirmed that towards NE the whole area has been affected by major movements. Two further landslides mapped in the IFFI inventory (Landslide $B$ and $C$ in Figure 11(a)) were partially identified with a less degree of precision since the slope is mainly covered by forest. Towards the upper portion of the Sapin valley the Ultrahelvetic units and the Monte Bianco-Mont Chètif crystalline complex are divided by the Penninic frontal thrust. The rocks belonging to the frontal portion of the Penninic units (calcschists, dolomites, limestones, chalk, gypsum, conglomerates and breccias) are highly tectonized and prone to the development of instability. In particular, the OBIA method recognized a whole secondary valley incised in Tarantasia breccias characterized by potential 
instability, which has been only partially mapped as R4 area in the $P A I$ inventory, and an adjacent area affected by falling and toppling (Figure 11) detected also by the PSI analysis. Landslide $A$ mapped in PAI (Figure 11(b)) could only partly be detected by the object-based analysis due to vegetation cover.

Figure 11. Comparison between OBIA results, (a) IFFI and (b) PAI maps in the Sapin Valley with indication of the larger instability phenomena underlain by orthophotos from 1998-1999.

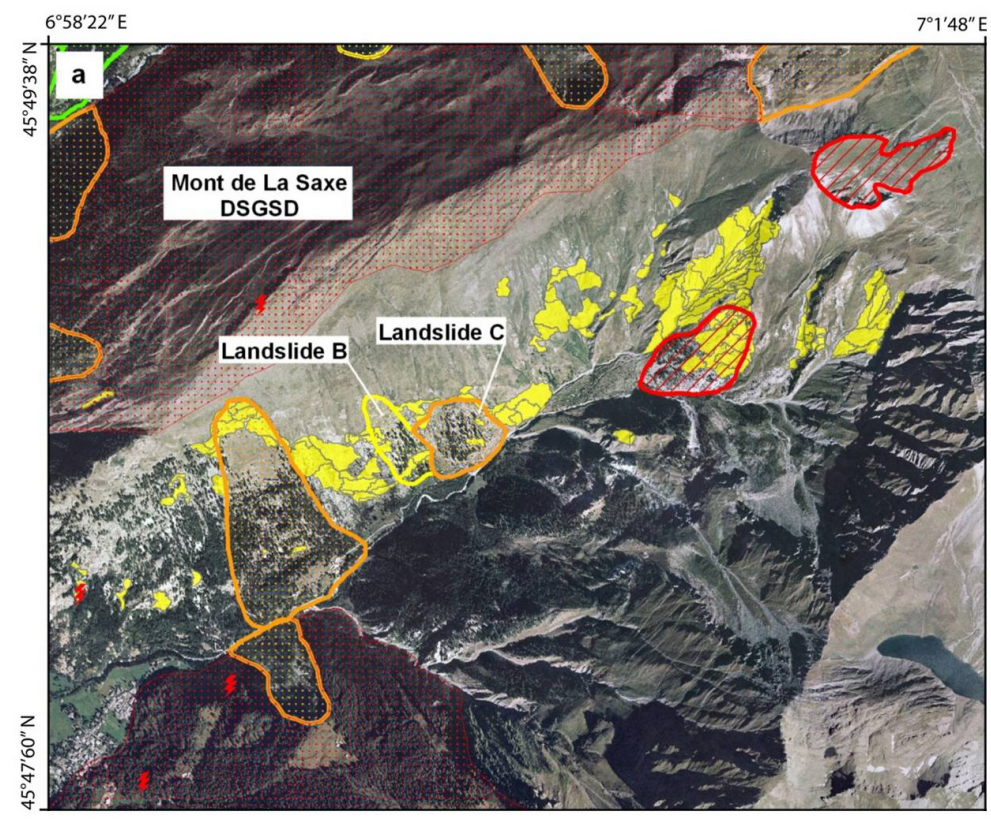

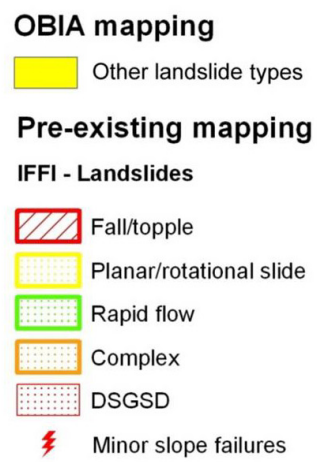

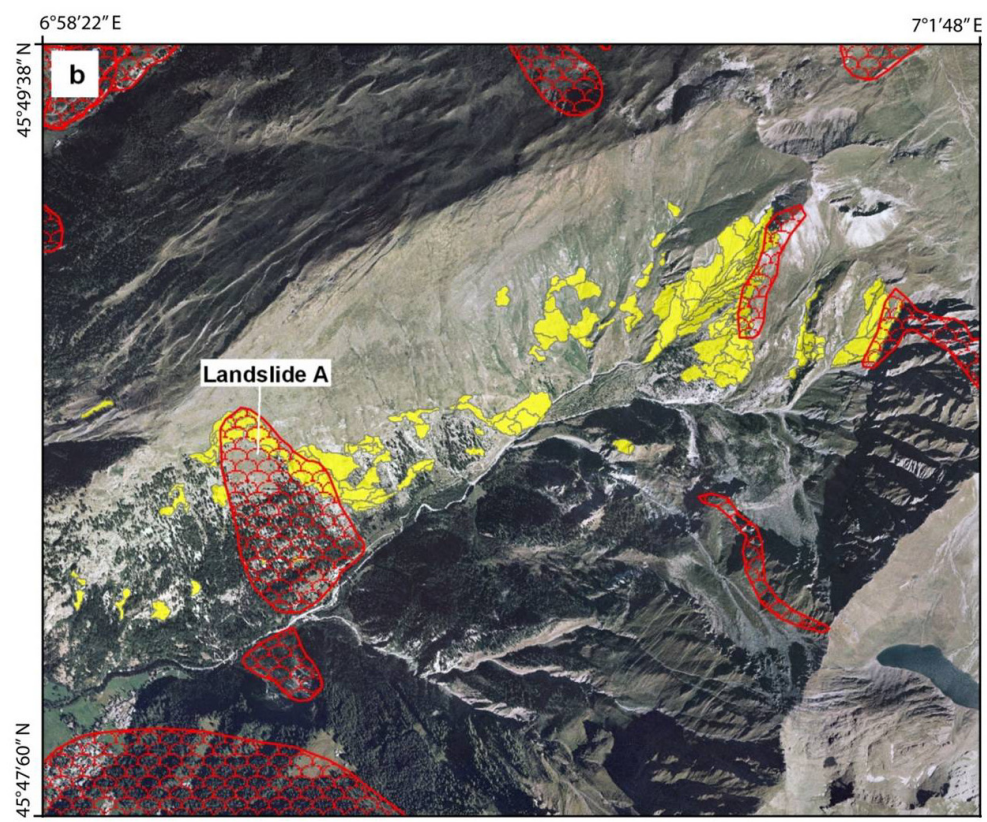

PAI - R3/R4 risk areas

VZ Flood

YYY Landslide

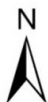

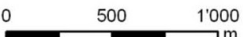

\subsubsection{Advanced Interpretation of Persistent Scatterers Data in 1992-2009}

InSAR techniques, especially the use of persistent scatterers (PS), provide valuable information on ground deformation [37-40]. To quantify the historical and recent deformation rates of the unstable areas identified through OBIA and to validate the semi-automated landslide recognition, we employed six datasets of persistent scatterers obtained by SPN processing of ascending and descending ERS1/2 
(1992-2000), ENVISAT ASAR and RADARSAT-1 (2004-2009) data, which allowed the recognition of more than 12,000 PS over the whole area $\left(\sim 70 \mathrm{~km}^{2}\right)$. Only low density of PS can be obtained for densely vegetated areas due to the absence of good radar reflectors and strong temporal decorrelation. On the other hand, several targets are detected on urban structures and exposed rocks, allowing the estimation of LOS (Line Of Sight) yearly velocities as well as time series of deformation for the investigated area from 1992 to 2009 with millimeter precision.

Of the 632 polygons identified through OBIA about 32\% are covered by PS data; in particular, estimates of ground deformation are available for 149 flow-like landslides and 54 areas affected by other landslide types by at least one of the six PS datasets. For E, SE and NE facing slopes the datasets exploiting the ascending acquisition geometry are providing higher densities of PS, while W, SW and NW facing slopes are better analyzed with descending acquisition geometries. This is justified by the geometric visibility and topographic distortions of SAR imagery in the ascending and descending configurations, which are more suitable to investigate slopes facing in the same direction of the employed LOS (i.e., E and $\mathrm{W}$ facing areas). On the other hand, slopes facing the satellite undergo layover and foreshortening effects. As for the NW facing Bois de Plan Cereux landslide (cf. Figure 3), although a good topographic visibility is achieved using the descending geometry, a dense vegetation cover prevents reflective scatterers to be identified in the radar imagery; and as a direct consequence, the SPN processing was not able to deliver appropriate results for this area.

Interpretation of 1992-2009 PS measures (recently called 'radar-interpretation'; [41,42]) supported the definition of boundaries and areas of unstable sectors identified within the pre-existing inventories ( $P A I$ and $I F F I$ ), and detected through OBIA. For those unstable sectors characterized by high densities of PS data within their boundaries, the estimation of average velocities was also performed, together with their classification according to Cruden and Varnes [13]. Due to intrinsic characteristics of PS data and their difficulties in the analysis of motions exceeding few tens of $\mathrm{cm} / \mathrm{yr}$, only extremely slow $(v<16 \mathrm{~mm} / \mathrm{yr})$ and very slow $(16 \mathrm{~mm} / \mathrm{yr} \leq v<1.6 \mathrm{~m} / \mathrm{yr})$ phenomena were detected. Two examples of validation of the OBIA results through radar-interpretation are analyzed below. They show the cross-comparison of the object-based detection with PS data, the main advantages of the combined use of these two types of datasets and their complementarities, as well as critical issues, which should be addressed through field checks and validation.

\subsection{Combined Use of OBIA and PS Interpretation for Integrated Landslide Mapping}

In the area of Sapin valley the object-based approach identified quite a steep area of $\sim 0.085 \mathrm{~km}^{2}$ classified as affected by slope instability and characterized by an average NDVI of 0.12 (Figure 12). This area was previously mapped within the IFFI inventory as affected by falls and topples. PSI data stacks gathered from ENVISAT and RADARSAT-1 descending data reveal average rates of deformation of about $13 \mathrm{~mm} / \mathrm{yr}$ (ENVISAT) and $15 \mathrm{~mm} / \mathrm{yr}$ (RADARSAT) along the LOS, confirming the presence of active ground instability occurring in this area. The slight difference in the velocities estimated by the two datasets is mainly justified by the different orientation of the LOS of ENVISAT and RADARSAT-1 satellites, which are characterized by different look angles (i.e., $\sim 23^{\circ}$ and $\sim 34^{\circ}$, respectively). Due to the local orientation of the unstable slope, which faces WSW and has an average inclination of $30^{\circ}$, the 
component of the motion captured through the RADARSAT geometry (i.e., $15 \mathrm{~mm} / \mathrm{yr}$ ) is higher than that observed by ENVISAT (i.e., $13 \mathrm{~mm} / \mathrm{yr}$ ).

Figure 12. Integrated landslide mapping in the Sapin valley area updating the IFFI pre-existing inventory (a) through the OBIA approach and (b) complemented through radar-interpretation of ENVISAT (2004-2009) and RADARSAT-1 (2005-2009) descending PS data. Landslide mapping and PS data are overlapped on the 1998-1999 orthophoto, displayed using grey scale. Negative velocity values for the identified PS represent LOS movements in the direction away from the sensor, while positive values represent movements towards the satellite sensor.
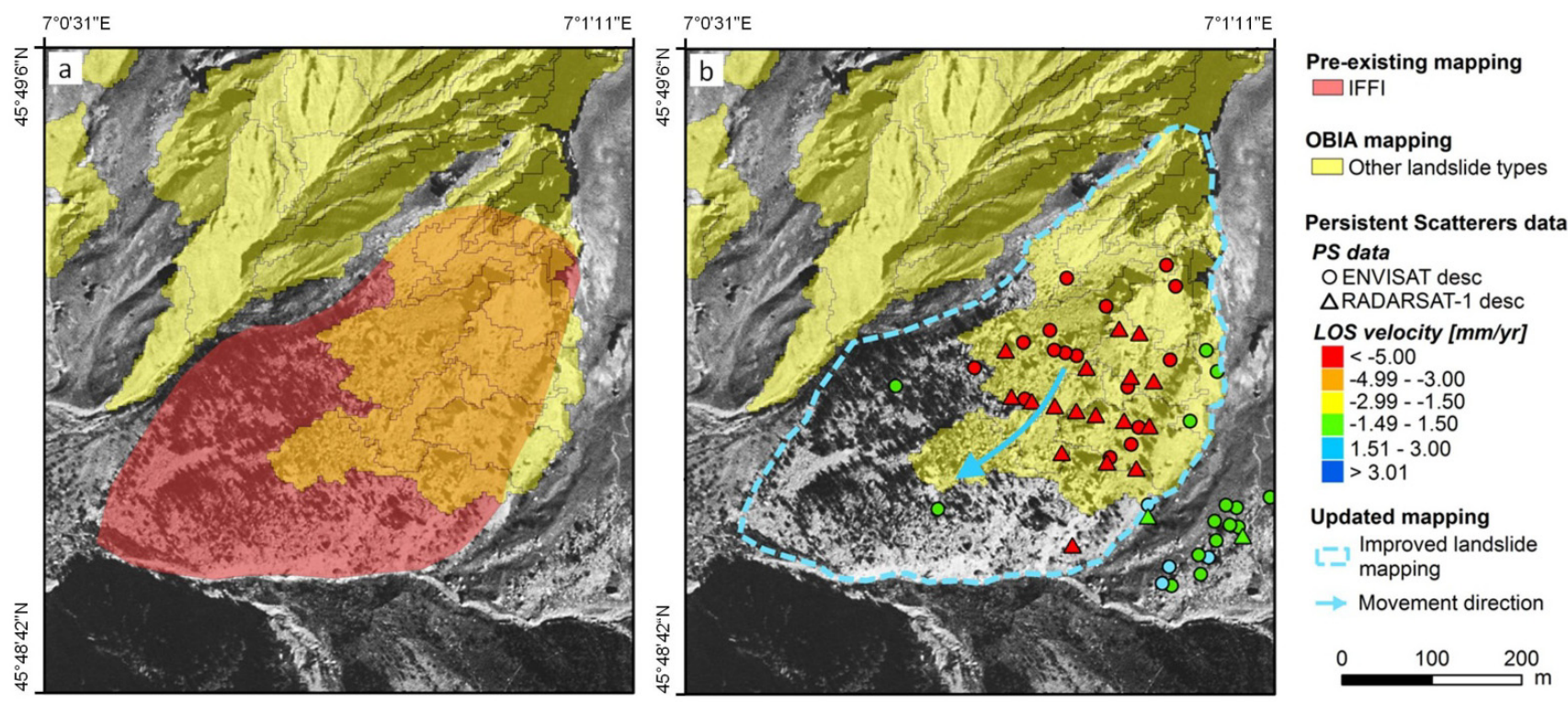

Assuming the direction of maximum slope as the main direction of deformation of this landslide-prone area, LOS rates estimated by both ENVISAT and RADARSAT were projected along the maximum slope direction. This projection produced an average velocity of about $17-18 \mathrm{~mm} / \mathrm{yr}$ for both datasets, which allowed classifying the landslide as a very slow phenomenon [13]. The combined interpretation of radar measures and landslide boundaries detected through OBIA facilitated the updating of the pre-existing landslide mapping, enlarging the unstable area in the uppermost sector of the slope (100 m NNE) and in its eastern portion (Figure 12). The total area of the unstable sector was updated from $\sim 0.141 \mathrm{~km}^{2}$ (IFFI) to $\sim 0.158 \mathrm{~km}^{2}$.

In the NE sector of Ferret valley, the OBIA method identified several unstable areas classified as flow-like landslides (Figure 13(a)), previously mapped within the IFFI inventory as affected by falls and topples; orientation of this sector is predominantly SE, with average slopes of $30-35^{\circ}$ and an NDVI ranging between 0.08 and 0.2. Due to slope orientation, the available PS data mostly belong to the ascending stacks of ENVISAT and RADARSAT-1 data (Figure 13(b)). These PS stacks reveal deformation velocities ranging between $\pm 3 \mathrm{~mm} / \mathrm{yr}$ (RADARSAT) and -4 and $+3 \mathrm{~mm} / \mathrm{yr}$ (ENVISAT), moving from the uppermost to the lowermost portions of the slope. An interpolated map of RADARSAT measured from 2005-2009 confirms this velocity distribution for all identified areas (Figure 13(c)). This behavior reflects the changes in the orientation of the main direction of displacement for the different portions of the slope. In the upper portion-characterized by higher 
inclinations - motion is mainly parallel to the slope, and produces negative deformation velocities (up to $-4 \mathrm{~mm} / \mathrm{yr}$ ) when projected along the ascending LOS direction. On the other hand, the lower portion is characterized by less steep slopes (up to $5^{\circ}$ ) and displacements show stronger horizontal components, which are seen by the ascending LOS as motions in the direction towards the sensor (i.e., positive velocities, up to $+3 \mathrm{~mm} / \mathrm{yr}$ ). Velocities projected along the maximum slope direction reveal for this unstable area up to 5-10 mm/yr; therefore, the movement can be classified as extremely slow [13]. Slight enlargement of the unstable area in its western sector was performed to include those areas highlighted by OBIA and showing geomorphologic evidences of ground instability (Figure 13(b)).

Figure 13. Integrated landslide mapping in the area of Ferret valley, refining the IFFI inventory through OBIA and radar-interpretation of ENVISAT (2004-2009) and RADARSAT-1 (2005-2009) ascending PS data. Pre-existing mapping from IFFI inventory and the results of the object-based analysis are shown in (a), while the updated landslide boundaries and PS data are shown in (b) and the interpolated LOS velocity of RADARSAT-1 PS in 2005-2009 in (c).
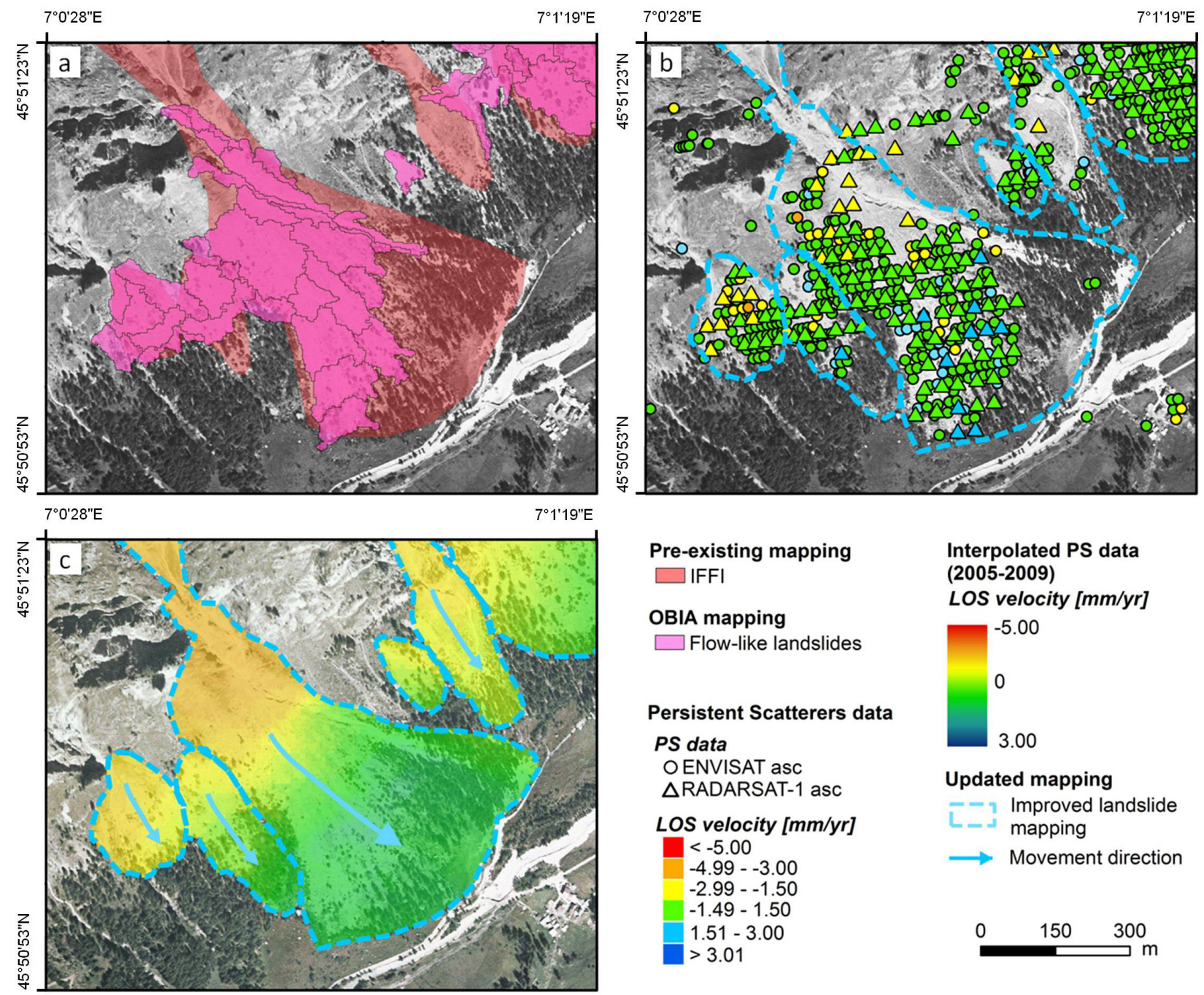

Pre-existing mapping $\square$ IFFI

OBIA mapping

$\square$ Flow-like landslides

Persistent Scatterers data $P S$ data

OENVISAT asc

$\triangle$ RADARSAT-1 asc

LOS velocity [mm/yr]

$<-5.00$

$-4.99--3.00$

$-2.99--1.50$

$-1.49-1.50$

$1.51-3.00$

$>3.01$
Interpolated PS data (2005-2009)

LOS velocity [mm/yr]

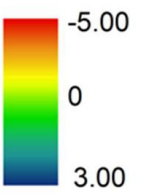

Updated mapping

$-\because$ Improved landslide

L_ mapping

$\longrightarrow$ Movement direction

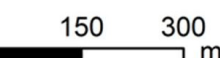




\section{Conclusions}

The presented approach demonstrates how landslide mapping can be improved and existing landslide inventories updated using a combination of object-based image analysis and radar-interpretation of ENVISAT and RADARSAT measures. In total, an area of $3.77 \mathrm{~km}^{2}$ was classified as landslide-affected by the object-based approach, including $1.68 \mathrm{~km}^{2}$ flow-like landslides (mainly channelized debris bodies and their depositional areas) and $2.09 \mathrm{~km}^{2}$ other landslide types (falls, topples, slides and spreads). OBIA offers fast and reliable methods for landslide detection and mapping by considering spectral, spatial, structural, contextual and also hierarchical properties while reducing the influence of per pixel spectral response patterns. During class modeling image-objects can be addressed individually and object-boundaries can be refined through applying pixel-based resizing algorithms. The flexibility of the approach allows for the integration of various data sets while making use of the most appropriate specific characteristics for detecting and classifying landslides. Thus, results with richer information content can be achieved overcoming some of the limitations found when relying on just one data set. On the other hand, uncertainty might be introduced through the combination of data sets from different points in time or with a different spatial resolution or by using absolute thresholds in the course of transforming expert knowledge into machine-based rules. The use of fuzzy rules during class modeling might be an alternative approach for analyzing complex natural phenomena, which hardly exhibits sharp boundaries. Validation of landslide mapping results originating from remote sensing data is a crucial aspect, but has been almost neglected in existing studies. That might be because existing landslide inventory maps, which could be used as a reference, are often outdated or too inaccurate or incomplete. As a result, they can present, at best, a rough reference indicating landslide-prone areas. Instead, such inventories could be regularly updated by using semi-automated and innovative methods. Ground truth data would probably constitute the best reference for validation, but such information often has limited availability and its acquisition is a work-intensive and expensive task and it is difficult to ascertain as landslide-prone regions are often hard to reach and to survey.

Within the presented study the results achieved through semi-automated object-based image analysis were validated against existing landslide inventories and outcomes from radar data analysis. Approximately $44.8 \%$ (i.e., $1.69 \mathrm{~km}^{2}$ ) of the detected landslides are also classified areas of the IFFI inventory and about $50.4 \%$ (i.e., $1.9 \mathrm{~km}^{2}$ ) spatially overlap with the R3 and R4 areas of the PAI map. The analysis of radar data (i.e., applying PSI technique) is commonly used in landslide research and has proved its usefulness over recent years. This study demonstrates how PSI results showing point-based movements can be used for validation purposes. Although some landslides are only detected by either OBIA or PSI due to some limitations (e.g., shadowed areas, absence of good radar reflectors), the results show a significant match when comparing image-objects with outcomes from radar data analysis. Of the 632 polygons identified through OBIA about $32 \%$ are covered by PS data; in particular, estimates of ground deformation are available for 149 flow-like landslides and 54 other landslide types. Further analysis should examine the methodological constraints attached to the comparison of point data with polygon data and taking into account different velocity rates.

Object-based image analysis offers a suitable and innovative framework to complement established procedures and brings in new dimensions regarding a more objective and efficient mapping and 
monitoring of landslides. However, more research is needed to make rulesets more intuitive, robust and transferable to different settings and conditions. Future research directions should aim at the further implementation of automated and operational workflows by a full integration of all available data sets (i.e., integrating both, optical and radar data supplemented by elevation information and ancillary data). Thus, it might be possible to automatically attach information about moving directions and rates to image-objects and to come up with fully integrated workflows and results.

\section{Acknowledgments}

The research leading to these results has received funding from the European Community's Seventh Framework Programme (FP7/2007-2013) under the SAFER (Services and Applications For Emergency Response) project, grant agreement no. 218802. ERS1/2, ENVISAT and RADARSAT images were provided under EC-ESA (European Commission-European Space Agency) GSC-DA (GMES Space Component Data Access), and were processed by Altamira Information within the SAFER project. Access to IFFI (Inventario dei Fenomeni Franosi in Italia) was possible through the ISPRA's WMS service, while PAI (Piano Stralcio di Bacino per l'Assetto Idrogeologico) was made available to the Earth Sciences Department-University of Firenze, Italy, by the Italian Civil Protection Department. The authors would also like to thank Barbara Friedl for supporting work done and Gaia Righini for her contribution during the selection of the satellite imagery.

\section{References}

1. Guha-Sapir, D.; Vos, F.; Below, R.; Ponserre, S. Annual Disaster Statistical Review 2010: The Numbers and Trends; Centre for Research on the Epidemiology of Disasters (CRED), Université catholique de Louvain: Brussels, Belgium, 2011; p. 41.

2. Tsai, F.; Hwang, J.-H.; Chen, L.C.; Lin T.H. Post-disaster assessment of landslides in southern Taiwan after 2009 Typhoon Morakot using remote sensing and spatial analysis. Nat. Hazards Earth. Syst. 2010, 10, 2179-2190.

3. Barlow, J.; Franklin, S.; Martin, Y. High spatial resolution satellite imagery, DEM derivatives, and image segmentation for the detection of mass wasting processes. Photogramm. Eng. Remote Sensing 2006, 72, 687-692.

4. Lu, P.; Stumpf, A.; Kerle, N.; Casagli, N. Object-oriented change detection for landslide rapid mapping. IEEE Geosci. Remote Sens. Lett. 2011, 8, 701-705.

5. Stumpf, A.; Kerle, N. Object-oriented mapping of landslides using Random Forests. Remote Sens. Environ. 2011, 115, 2564-2577.

6. Debella-Gilo, M.; Kääb, A. Measurement of surface displacement and deformation of mass movements using least squares matching of repeat high resolution satellite and aerial images. Remote Sens. 2012, 4, 43-67.

7. Borghuis, A.M.; Chang, K.T.; Lee, H.Y. Comparison between automated and manual mapping of typhoon-triggered landslides from SPOT-5 imagery. Int. J. Remote Sens. 2007, 28, 1843-1856.

8. Nichol, J.E.; Wong, M.S. Satellite remote sensing for detailed landslide inventories using change detection and image fusion. Int. J. Remote Sens. 2005, 26, 1913-1926. 
9. Mondini, A.C.; Chang, K.T.; Yin, H.Y. Combining multiple change detection indices for mapping landslides triggered by typhoons. Geomorphology 2011, 134, 440-451.

10. Martha, T.R.; Kerle, N.; Jetten, V.; van Westen, C.J.; Kumar, K.V. Characterising spectral, spatial and morphometric properties of landslides for semi-automatic detection using object-oriented methods. Geomorphology 2010, 116, 24-36.

11. Blaschke, T. Object based image analysis for remote sensing. ISPRS J. Photogramm. 2010, 65, $2-16$.

12. Lang, S. Object-Based Image Analysis for Remote Sensing Applications: Modeling Reality-Dealing with Complexity. In Object-Based Image Analysis: Spatial Concepts for Knowledge-Driven Remote Sensing Applications; Blaschke, T., Lang, S., Hay, G.J., Eds.; Springer: Berlin/Heidelberg, Germany, 2008; pp. 3-28.

13. Cruden, D.M.; Varnes, D.J. Landslide Types and Processes. In Landslides: Investigation and Mitigation; Turner, A.K., Schuster, R.L., Eds; Sp. Rep. 247; Transportation Research Board, National research Council, National Academy Press: Washington, DC, USA, 1996; pp. 36-75.

14. Lahousse, T.; Chang, K.T.; Lin, Y.H. Landslide mapping with multi-scale object-based imaged analysis- a case study in the Baichi watershed, Taiwan. Nat. Hazards Earth. Syst. 2011, 11, 1-12.

15. Martha, T.R.; Kerle, N.; van Westen, C.J.; Jetten, V.; Kumar, K.V. Segment optimization and data-driven thresholding for knowledge-based landslide detection by object-based image analysis. IEEE Trans. Geosci. Remote Sens. 2011, 49, 4928-4943.

16. Martin, Y.E.; Franklin, S.E. Classification of soil and bedrock-dominated landslides in British Columbia using segmentation of satellite imagery and DEM data. Int. J. Remote Sens. 2005, 26, 1505-1509.

17. Moine, M.; Puissant, A.; Malet, J.P. Detection of Landslides from Aerial and Satellite Images with a Semi-Automatic Method. Application to the Barcelonnette Basin (Alps-de-Haute-Provence). In Landslide Processes: From Geomorphological Mapping to Dynamic Modelling; Malet, J.-P., Remaitre, A., Bogaard, T., Eds.; CERG: Strasbourg, France, 2009; pp. 63-68.

18. Rau, J.Y.; Jhan, J.P.; Lo, C.F.; Lin, Y.S. Landslide Mapping Using Imagery Acquired by a Fixed-Wing UAV. In Proceedings of the International Conference on Unmanned Aerial Vehicle in Geomatics (UAV-g), Zurich, Switzerland, 14-16 September 2011; In International Archives of the Photogrammetry, Remote Sensing and Spatial Information Sciences; 2011; Volume XXXVIII, p. 6.

19. Hölbling, D.; Füreder, P. A (semi-)automated object-based approach for landslide detection based on SPOT-5 imagery and digital elevation data. Geophys. Res. Abs. 2011, 13, EGU 2011-6786.

20. Aksoy, B.; Ercanoglu, M. Landslide identification and classification by object-based image analysis and fuzzy logic: An example from the Azdavay region (Kastamonu, Turkey). Comput. Geosci. 2012, 38, 87-98.

21. Drăgut, L.; Blaschke, T. Automated classification of landform elements using object-based image analysis. Geomorphology 2006, 81, 330-344.

22. Drăgut, L.; Eisank, C. Automated object-based classification of topography from SRTM data. Geomorphology 2012, 141-142, 21-33.

23. Lang, S.; Albrecht, F.; Kienberger, S.; Tiede, D. Object validity for operational tasks in a policy context. J. Spatial Sci. 2010, 55, 9-22. 
24. Dal Piaz, G.V.; Bistacchi, A.; Massironi, M. Geological outline of the Alps. Episodes 2004, 28, 174-179.

25. Roure, F.; Bergerat, F.; Damotte, B.; Mugnier, J.L.; Polino, R. The ECORS-CROP Alpine seismic traverse. Memoires de la Societe Geologique de France 1996, 170, 1-113.

26. Bernabini, M.; Polino, R.; Nicolich, R. Seismic lines CROP-ECORS across the Western Alps. In Mem. Descr. Carta Geol. d'It. 2003, LXII; pp. 89-96.

27. Bucher, S.; Ulardic, C.; Bousquet, R.; Ceriani, S.; Fügenschuh, B.; Gouffon, Y.; Schmid, S.M. Tectonic evolution of the Briançonnais units along a transect (ECORS-CROP) through the Italian-French Western Alps. Eclogae. Geol. Helv. 2004, 97, 321-345.

28. Deline, P.; Broccolato, M.; Noetzli, J.; Ravanel, L.; Tamburini, A. The December 2008 Crammont rock avalanche, Mont Blanc massif area, Italy. Geophys. Res. Abs. 2010, 12, EGU 2010-10388.

29. Arnaud, A.; Adam, N.; Hanssen, R.; Inglada, J.; Duro, J.; Closa, J.; Eineder M. ASAR ERS Interferometric Phase Continuity. In Proceedings of the International Geoscience and Remote Sensing Symposium (IGARSS'03), Toulouse, France, 21-25 July 2003; pp. 1133-1135.

30. Duro, J.; Inglada, J.; Closa, J.; Adam, N.; Arnaud, A. High Resolution Differential Interferometry Using Time Series of ERS and ENVISAT SAR Data. In Proceedings of FRINGE 2003 Workshop, Frascati, Italy, 1-5 December 2003; p. 6.

31. Tiede, D.; Lang, S.; Albrecht, F.; Hölbling, D. Object-based class modeling for cadastre-constrained delineation of geo-objects. Photogramm. Eng. Remote Sensing 2010, 76, 193-202.

32. Tiede, D.; Lang, S.; Hoffmann, C. Type-Specific Class Modelling for One-Level Representation of Single Trees. In Object-Based Image Analysis: Spatial Concepts for Knowledge-Driven Remote Sensing Applications; Blaschke, T., Lang, S., Hay, G.J., Eds.; Springer: Berlin, German, 2008; pp. 133-151.

33. Drăguţ, L.; Tiede, D.; Levick, S.R. ESP: A tool to estimate scale parameter for multiresolution image segmentation of remotely sensed data. Int. J. Geogr. Inf. Sci. 2010, 24, 859-871.

34. Trimble Documentation. eCognition ${ }^{\circledR}$ Developer 8.64.0 Reference Book; Trimble Germany GmbH: Munich, Germany, 2010.

35. Varnes, D.J. Slope Movements: Types and Processes. In Landslides: Analysis and Control; Schuster, R.L., Krizek, R.J., Eds.; Special Report 176; Transportation Research Board, National Academy of Sciences: Washington, DC, USA, 1978; pp. 11-33.

36. Agenzia per la Protezione dell'Ambiente e per i Servizi Tecnici (APAT). Rapporto Sulle Frane in Italia, Il Progetto IFFI: Metodologia, Risultati e Rapporti Regionali; APAT Report 78; APAT: Rome, Italy, 2007.

37. Crosetto, M.; Monserrat, O.; Cuevas, M.; Crippa, B. Spaceborne differential SAR interferometry: Data analysis tools for deformation measurement. Remote Sens. 2011, 3, 305-318.

38. Zhou, X.; Chang, N.-B.; Li, S. Applications of SAR Interferometry in earth and environmental science research. Sensors 2009, 9, 1876-1912.

39. Meisina, C.; Zucca, F.; Notti, D.; Colombo, A.; Cucchi, A.; Savio, G.; Giannico, C.; Bianchi, M. Geological interpretation of PSInSAR data at regional scale. Sensors 2008, 8, 7469-7492.

40. Delacourt, C.; Raucoules, D.; Le Mouélic, S.; Carnec, C.; Feurer, D.; Allemand, P.; Cruchet, M. Observation of a large landslide on La Reunion Island using differential SAR Interferometry (JERS and Radarsat) and correlation of optical (Spot5 and Aerial) images. Sensors 2009, 9, 616-630. 
41. Farina, P.; Casagli, N.; Ferretti, A. Radar-interpretation of InSAR Measurements for Landslide Investigations in Civil Protection Practices. In Proceedings of the 1st North American Landslide Conference, Vail, CO, USA, 3-8 June 2007; pp. 272-283.

42. Cigna, F.; Del Ventisette, C.; Liguori, V.; Casagli, N. Advanced radar-interpretation of InSAR time series for mapping and characterization of geological processes. Nat. Hazards. Earth. Syst. 2011, 11, 865-881.

(C) 2012 by the authors; licensee MDPI, Basel, Switzerland. This article is an open access article distributed under the terms and conditions of the Creative Commons Attribution license (http://creativecommons.org/licenses/by/3.0/). 